\title{
Ruthenium 4d-to-2p X-ray Emission Spectroscopy: A Simultaneous Probe of the Metal and the Bound Ligands
}

\author{
Natalia Levin, Sergey Peredkov, Thomas Weyhermüller, Olaf Rüdiger, Nilson B. Pereira, \\ Daniel Grötzsch, Aleksandr Kalinko, and Serena DeBeer*
}

Cite This: Inorg. Chem. 2020, 59, 8272-8283

Read Online

ACCESS

Llll Metrics \& More

Article Recommendations

Supporting Information

ABSTRACT: Ruthenium 4d-to-2p X-ray emission spectroscopy (XES) was systematically explored for a series of $\mathrm{Ru}^{2+}$ and $\mathrm{Ru}^{3+}$ species. Complementary density functional theory calculations were utilized to allow for a detailed assignment of the experimental spectra. The studied complexes have a range of different coordination spheres, which allows the influence of the ligand donor/acceptor properties on the spectra to be assessed. Similarly, the contributions of the site symmetry and the oxidation state of the metal were analyzed. Because the $4 \mathrm{~d}-$ to- $2 \mathrm{p}$ emission lines are dipole-allowed, the spectral features are intense. Furthermore, in contrast with $\mathrm{K}$ - or L-edge X-ray absorption of $4 \mathrm{~d}$ transition metals, which probe the unoccupied levels, the observed $4 p$-to- $2 p$ $\mathrm{XES}$ arises from electrons in filled-ligand- and filled-metal-based

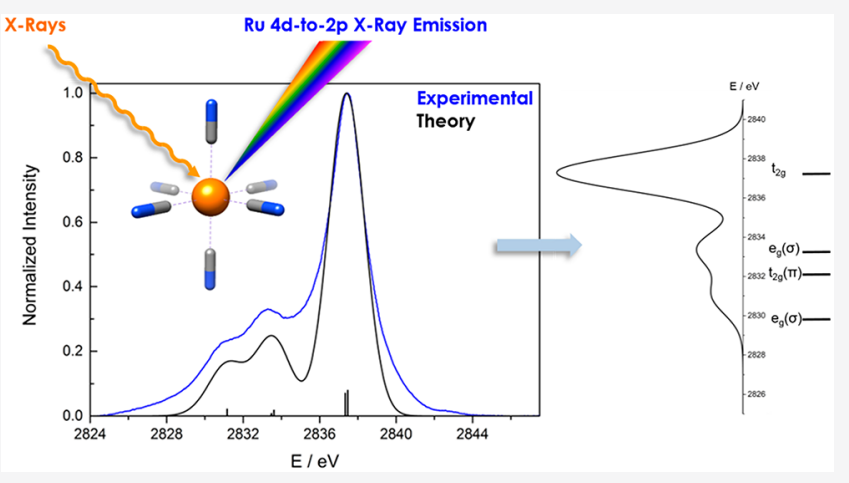
orbitals, thus providing simultaneous access to the ligand and metal contributions to bonding. As such, $4 \mathrm{~d}$-to- $2 \mathrm{p}$ XES should be a promising tool for the study of a wide range of $4 \mathrm{~d}$ transition-metal compounds.

\section{INTRODUCTION}

Ruthenium is a $4 \mathrm{~d}$ transition metal (TM) that is found in formal oxidation states ranging from +8 to -2 . It is a relatively rare element, being found at only 100 parts per trillion in the earth's crust. Despite its scarcity, however, ruthenium has found use in numerous areas of research, spanning photochemistry and photophysics, ${ }^{1,2}$ catalysis (including water oxidation, ${ }^{3,4}$ metathesis, ${ }^{5}$ and asymmetric hydrogenation of ketones $^{6}$ ), and bioinorganic chemistry (including anticancer drugs $^{7,8}$ and as model species for heme metalloenzymes ${ }^{9,10}$ ).

To rationalize structure-function relations or to design more efficient catalysis, a detailed understanding of the geometric and electronic structure of $\mathrm{Ru}$ and its coordination environment is highly desirable. In this regard, X-ray spectroscopic techniques are very attractive as elementselective probes of a metal of interest. For $\mathrm{Ru}$, K-edge X-ray absorption spectroscopy (XAS) has seen a wide range of applications. ${ }^{11-16}$ However, because of the intrinsic spectral broadening resulting from the short $\mathrm{Ru} 1 \mathrm{~s}$ core-hole lifetime, ${ }^{17}$ the $\mathrm{Ru} \mathrm{K}$-edge spectra are typically broad and rarely exhibit well-defined 1s-to-4d pre-edge features. Nevertheless, complemented with other techniques or computational tools, $\mathrm{Ru}$ K-edge XAS allows the characterization of $\mathrm{Ru}$ species under both $e x$ situ $^{11-16}$ and in situ ${ }^{18-20}$ conditions. Alternatively, one can utilize Ru L-edge XAS, which, due to the dipole-allowed nature of the $2 \mathrm{p}$-to- $4 \mathrm{~d}$ transitions, provides a more direct probe of the empty $4 \mathrm{~d}$ orbitals localized on the $\mathrm{Ru} .^{16,21-26}$ As such, the $\mathrm{Ru}$ L-edge is a useful probe of the oxidation state and, to some extent, the site symmetry. To obtain information about the ligand environment, one can utilize the Ru extended X-ray absorption fine structure (EXAFS) (most typically at the Ru Kedge) to extract information about the ligands surrounding $\mathrm{Ru}$ and their distances. However, because EXAFS is a scatteringbased method, similar mass atoms, such as $\mathrm{C}, \mathrm{N}$, and $\mathrm{O}$ (or $\mathrm{P}$, $\mathrm{S}$, and $\mathrm{Cl}$ ), cannot be distinguished.

It is here that Ru X-ray emission spectroscopy (XES) in the valence region is potentially a very promising tool. In an XES experiment, one monitors the fluorescence that occurs when an electron from a higher energy level refills a core hole on the photoabsorber. These emission lines are referred to as Kemission lines when an electron fills a 1 s core hole and Lemission lines when an electron refills a $2 \mathrm{~s} / 2 \mathrm{p}$ core hole. The former has been relatively intensely studied for $3 \mathrm{~d}$ TMs, and limited applications for $4 \mathrm{~d}$ TMs have been reported. ${ }^{27-30}$ The weak valence-to-1s (or valence-to-core, $\mathrm{VtC}$ ) $\mathrm{XES}$ region, which results from an electron in a ligand valence orbital refilling a $1 \mathrm{~s}$ core hole at the metal, has been shown to provide

Received: March 3, 2020

Published: May 11, 2020 


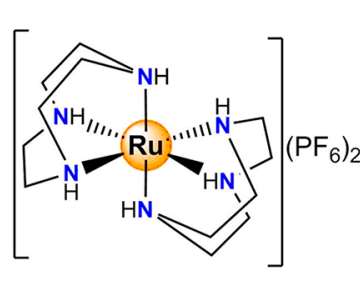

$\left[\mathrm{Ru}(\mathrm{tacn})_{2}\right]\left(\mathrm{PF}_{6}\right)_{2}$

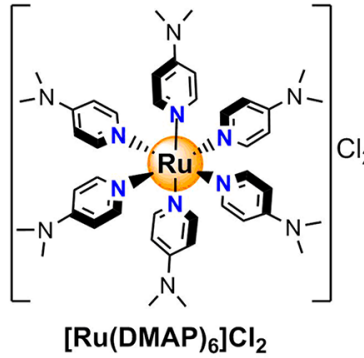

$\left[\begin{array}{l}\left.\mathrm{Ru}\left(\mathrm{NH}_{3}\right)_{6}\right] \mathrm{Cl}_{3} \\ \mathrm{NH}_{3} / \ldots, \ldots\end{array}\right.$

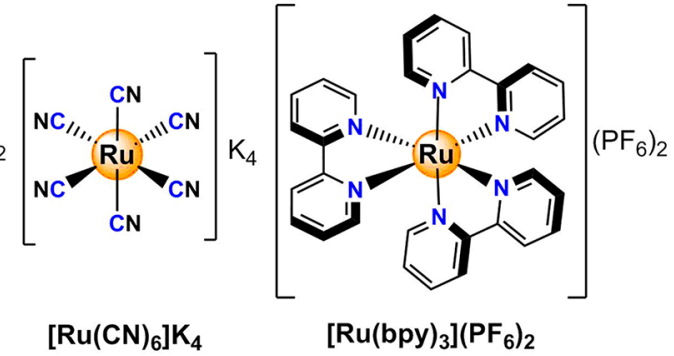

$\left[\mathrm{Ru}(\mathrm{CN})_{6}\right] \mathrm{K}_{4}$

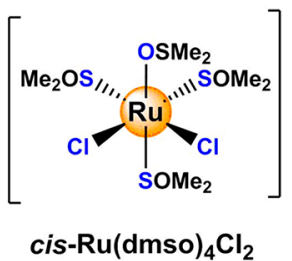

Figure 1. Structures of the investigated ruthenium model complexes.

a valuable probe of the ligand identity $(\mathrm{C}, \mathrm{N}, \mathrm{O}),{ }^{31-33}$ the protonation state $\left(\mathrm{O}^{2-}\right.$ vs $\left.\mathrm{OH}^{-}\right),{ }^{30,34-36}$ and the degree of bond activation (e.g., peroxo vs superoxo). ${ }^{37-40}$ However, because valence-to-1s XES transitions gain intensity through a small amount of metal $\mathrm{p}$ mixing into the ligand orbitals (imparting the transition with dipole-allowed character), ${ }^{28}$ the spectral transitions are intrinsically weak and, in most cases, provide little direct insight into the filled metal $\mathrm{d}$ orbitals (because $d$ to $s$ transitions are formally dipole-forbidden).

The ability to directly probe the filled ligand and the filled metal d orbitals is clearly of great interest in obtaining detailed information about the bonding, the coordination environment, and the oxidation state of the metal site in the same experimental spectrum. This could be achieved by following $3 \mathrm{~d}$-to- $2 \mathrm{p}$ or $4 \mathrm{~d}$-to- $2 \mathrm{p}$ XES, for which the transitions are all dipole-allowed. Interestingly, however, valence to $2 \mathrm{p}$ XES lines have been relatively unexplored for both $3 \mathrm{~d}$ or $4 \mathrm{~d}$ TMs. ${ }^{41}$ In the case of $3 \mathrm{~d}$ TMs, this is largely due to the very low probability of a fluorescence event occurring in this energy regime, thus making nonresonant XES prohibitively challenging and instead requiring a resonant XES (or RIXS) measurement. For $4 \mathrm{~d}$ TMs, the probability of a d-to-p fluorescence decay occurring is significantly increased relative to $3 \mathrm{~d}$ TMs, making nonresonant 4d-to-p XES more readily accessible. Furthermore, because the valence region is composed of both filled ligands and, at higher energy, filled $\mathrm{d}$ orbitals, one can, in principle, map out the $\mathrm{d}$ character in both the filled ligand and filled metal $d$ orbitals. To our knowledge, however, no systematic exploration of these spectra has been made. Herein we systematically explore the chemical information content of $\mathrm{Ru} 4 \mathrm{~d}$-to-2p XES spectra (also known as $\mathrm{L} \beta_{2}$ lines in the physics literature) for a series of molecular $\mathrm{Ru}$ complexes.

The chosen series of complexes includes $\mathrm{Ru}^{\mathrm{II}}$ species, where the coordinating ligands range from a $\sigma$ donor in $\left[\mathbf{R u}^{\mathrm{II}}(\mathbf{t a c n})_{2}\right]^{2+}$, to a $\pi$ donor in $\left[\mathbf{R u}^{\mathrm{II}}(\mathrm{DMAP})_{6}\right]^{2+}$, to the usually considered $\pi$ acceptor $^{42}$ in $\left[\mathbf{R u}^{\mathrm{II}}(\mathbf{C N})_{6}\right]^{4-}$ and a $\pi$ acceptor in $\left[\mathbf{R u}^{\mathrm{II}}(\mathbf{b p y})_{3}\right]^{2+}$ (Figure 1$)$. An oxidized analogue with a $\sigma$-donor ligand environment $\left[\mathbf{R u}^{\mathrm{III}}\left(\mathrm{NH}_{3}\right)_{6}\right]^{3+}$ was included to evaluate the effect in the $4 \mathrm{~d}$-to- $2 \mathrm{p}$ transitions upon changing the oxidation state. Finally, a less symmetric example, cis-[ $\left[\mathbf{R u}^{\mathrm{II}}(\mathbf{d m s o})_{4} \mathbf{C l}_{2}\right]$, was utilized to examine the effects of lowering the site symmetry.
The experimental spectra are correlated to density functional theory (DFT) calculated spectra. The strong agreement between experiment and theory grants access for clear assignments of the observed spectral features to be made. Importantly, we demonstrate that $\mathrm{Ru} 4 \mathrm{~d}$-to-2p XES allows for the filled ligand and metal $4 \mathrm{~d}$ orbitals to be simultaneously probed, providing access to the nature of the ligand, the oxidation state of the metal, and the covalency between the metal and the ligand. We thus believe that 4d-to-2p XES has great potential for investigating the electronic structure of $\mathrm{Ru}$ containing materials as well as all other $4 \mathrm{~d}$ TMs.

\section{METHODS}

2.1. Materials. Potassium hexacyanoruthenate(II) hydrate $\mathrm{K}_{4}[\mathrm{Ru}-$ $\left.(\mathrm{CN})_{6}\right] \cdot x \mathrm{H}_{2} \mathrm{O}$, hexaammineruthenium(III) chloride $\left[\mathrm{Ru}^{\text {III }}\left(\mathrm{NH}_{3}\right)_{6}\right]$ $\mathrm{Cl}_{3}$, and $\left[\mathrm{Ru}^{\mathrm{II}}(\mathrm{bpy})_{3}\right]\left(\mathrm{PF}_{6}\right)_{2}$ (bpy $=2,2^{\prime}$-bipyridine) were purchased from Sigma-Aldrich and used without further purification. cis$\mathrm{Ru}^{\mathrm{II}}(\mathrm{dmso})_{4} \mathrm{Cl}_{2}(\mathrm{dmso}=$ dimethyl sulfoxide $)$ and $\left[\mathrm{Ru}^{\mathrm{II}}(\mathrm{DMAP})_{6}\right] \mathrm{Cl}_{2}$ (DMAP $=4$-dimethylaminopyridine $)$ were prepared according to a published procedures. ${ }^{43,44}\left[\mathrm{Ru}^{\mathrm{II}}(\operatorname{tacn})_{2}\right]\left(\mathrm{PF}_{6}\right)_{2}(\operatorname{tacn}=1,4,7$-triazacyclononane) was synthesized following the reported procedure for $\left[\mathrm{Ru}^{\mathrm{II}}(\operatorname{tacn})_{2}\right](\mathrm{OTf})_{2}{ }^{45}$ employing the standard $\mathrm{Ru}$ precursor cis$\mathrm{Ru}^{\mathrm{II}}(\mathrm{dmso}){ }_{4} \mathrm{Cl}_{2}{ }^{43}$ and replacing the precipitating agent with $\mathrm{NH}_{4} \mathrm{PF}_{6}$.

2.2. XES Measurements. All samples were measured in the solid state at room temperature. The pure solids were ground to a fine powder and packed into $1 \mathrm{~mm}$ thick aluminum sample holders. The irradiated side of the cell was covered with $8 \mu \mathrm{m}$ Kapton film to maximize the detected X-ray photons. In the case of $\left[\mathrm{Ru}(\mathrm{bpy})_{3}\right]$ $\left(\mathrm{PF}_{6}\right)_{2}$, an $0.8 \mu \mathrm{m}$ aluminum window covered with $8 \mu \mathrm{m}$ polypropylene was used to attenuate a beam-induced visible fluorescent signal which otherwise masked the desired L-emission lines.

Preliminary experiments were done at the XAS beamline P64 at the PETRA III storage ring, capable of delivering an $8 \times 10^{12} \mathrm{ph} / \mathrm{s}$ photon beam at $5 \mathrm{keV}$ incident energy in a $40 \mu \mathrm{m} \times 200 \mu \mathrm{m}(\mathrm{V} \times \mathrm{H})$ spot by means of a $\mathrm{Si}(111)$ monochromator. The final measurements (and therefore all data shown here) were performed at the recently constructed PINK tender X-ray beamline at BESSY II. Currently, the PINK beamline is operated in commissioning mode. A considerable gain in fluorescence signal could be obtained by using a multilayer monochromator $\left(\sim 100 \mathrm{eV}\right.$ band pass), which provided $2 \times 10^{13}$ photons/s and a lower excitation energy of $4 \mathrm{keV}$. The beam size on the sample was $30 \mu \mathrm{m} \times 500 \mu \mathrm{m}(\mathrm{V} \times \mathrm{H})$.

All spectra were collected using an in-house-designed energydispersive vacuum spectrometer $\left(10^{-5} \mathrm{mbar}\right.$ internal pressure $)$ based on von Hamos geometry with a vacuum sample chamber environment 

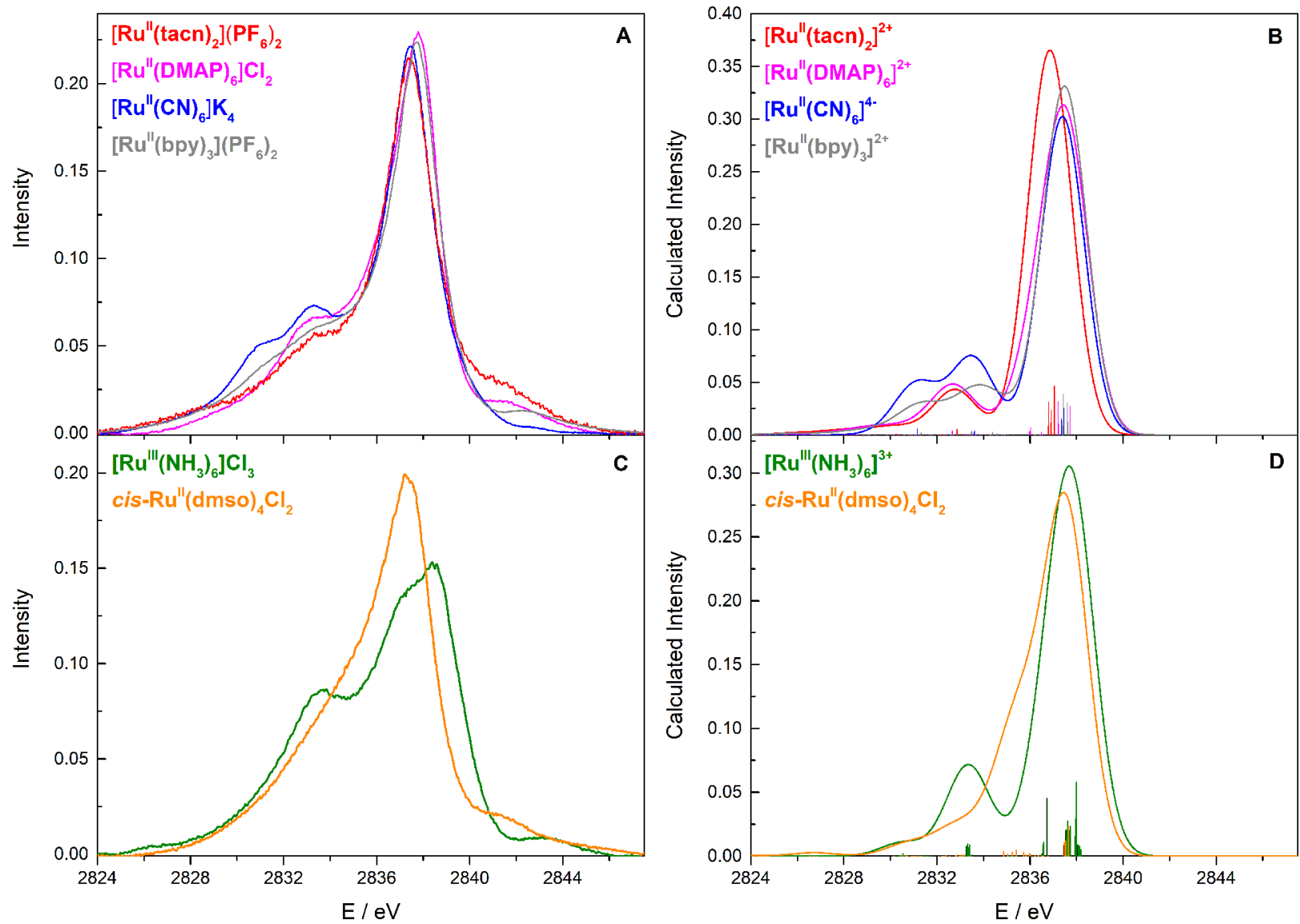

Figure 2. Comparison between $(A, C)$ experimental and (B,D) DFT calculated Ru 4d-to-2p XES spectra for $\left[\mathbf{R u}^{\mathrm{II}}(\mathbf{t a c n})_{2}\right]^{2+}(\mathrm{red})$, $\left[\mathrm{Ru}^{\mathrm{II}}(\mathrm{DMAP})_{6}\right]^{2+}$ (pink), $\left[\mathrm{Ru}^{\mathrm{II}}(\mathrm{CN})_{6}\right]^{4-}$ (blue), $\left[\mathrm{Ru}^{\mathrm{II}}(\mathrm{bpy})_{3}\right]^{2+}$ (gray), $\left[\mathrm{Ru}^{\mathrm{III}}\left(\mathrm{NH}_{3}\right)_{6}\right]^{3+}$ (green) and cis- $\left[\mathrm{Ru}^{\mathrm{II}}\left(\mathrm{dmso}_{4} \mathrm{Cl}_{2}\right]\right.$ (orange). Both experimental and calculated spectra are normalized to the area. A broadening of $2.2 \mathrm{eV}$ and an energy shift of $26.5 \mathrm{eV}$ were applied to the calculated spectra.

(5 mbar working pressure). The analyzer was set up in a vertical dispersion direction, taking advantage of the small vertical beam size to improve the energy resolution. A cylindrically bent $25 \mathrm{~mm} \times 100$ $\mathrm{mm} \alpha$-quartz $(10 \overline{1} 2)$ crystal $(d=2.282 \AA)$ with a bending radius of $R$ $=250 \mathrm{~mm}$ dispersed incoming fluorescence radiation onto a vacuumcompatible charge-coupled device (CCD) camera with a $26 \mu \mathrm{m} \times 26$ $\mu$ m pixel size. The $26.6 \mathrm{~mm} \times 7 \mathrm{~mm}$ detector chip accepted an energy window of $2810-2850 \mathrm{eV}$ (Bragg angles of $\theta=75.3-72.6^{\circ}$ ).

Calibration of the energy scale was achieved by measuring reference X-ray emission lines in the same instrumental configuration. The employed sample holder allowed for three samples as well as two references to be mounted for energy calibration: $\mathrm{Pd}$ foil and $\mathrm{KCl}$ powder. To establish the energy scale, the $\mathrm{Pd} \mathrm{L} \alpha_{1}, \operatorname{Pd~} \mathrm{L} \alpha_{2}$, and $\mathrm{Cl}$ $\mathrm{K} \beta_{13}$ emission lines were calibrated to $2838.61,2833.29$, and 2815.6 $\mathrm{eV}$, respectively. ${ }^{46}$ Energies were translated into Bragg angles, and a linear fit was applied.

Damage scans were performed for all samples. Data corresponding to undamaged samples were selected through the comparison of sequential partial sum spectra. In all cases, the data were collected in continuous motion, employing the speed and the total irradiation dose per pass, as determined by the damage scans. The employed speed varied from 200 to $500 \mu \mathrm{m} \cdot \mathrm{s}^{-1}$, and the total exposure was between 4 and $8 \mathrm{~s}$ per spot. With a longer exposure time, the spectra of $\left[\mathrm{Ru}\left(\mathrm{NH}_{3}\right)_{6}\right] \mathrm{Cl}_{3}$ showed signs of damage, whereas no change in the spectra was seen for the other studied complexes for exposure times up to $200 \mathrm{~s}$.

2.3. Theoretical Calculations. All calculations were performed with the ORCA quantum chemistry software package. ${ }^{47,48}$ For all ruthenium species, the calculations employed DFT with the B3LYP ${ }^{49-52}$ hybrid functional and the "old-zora-TZVP" recontracted scalar relativistic all-electron basis set, as well as the relativistic approximation ZORA. An auxiliary basis set for Coulomb fitting was employed: SARC/J. ${ }^{53}$ The auxiliary basis set was automatically generated by the keyword AutoAux. ${ }^{54} \mathrm{~A}$ tight self-consistent field (SCF) convergence threshold was chosen. An increased grid was used during the SCF iterations (Grid4), and no grid was used in the final energy evaluation after SCF convergence. To enhance the SCF convergence procedure, a combined method was utilized, employing an alternative algorithm to the direct inversion in iterative subspace (DIIS), KDIIS, and when the calculation was close to convergence, the program switched to a second-order SCF (SOSCF). ${ }^{55,56}$ The conductor-like polarizable continuum model (CPCM) was used for charge compensation in all calculations. In particular, during the geometry optimizations, a more detailed cavity was specified to ensure that a minimal stationary point was reached, tested by computing the vibrational spectra. To this end, the number of points around each atom used to define the cavity with the GEPOL algorithm was explicitly defined to be 110 Lebedev grid points. ${ }^{57}$ XES calculations were performed utilizing previously established protocols, ${ }^{58}$ with optimized structures and the standard CPCM model. For $\left[\mathrm{Ru}^{\mathrm{II}}(\mathrm{DMAP})_{6}\right]^{2+}$, the crystallographic geometry was used for the XES calculations. ${ }^{44}$ For the XES calculations, the same functional, basis set, and SCF convergence methods as those in the geometry optimizations were used. To include the spin-orbit in the calculations, the keywords CoreOrbSOC and DoSOC true were employed. A $2.2 \mathrm{eV}$ broadening was applied to the calculated spectra, in agreement with the natural broadening of the tabulated $\mathrm{L}_{3}$ lines. ${ }^{17}$ A constant $26.5 \mathrm{eV}$ shift in energy was applied to the DFT calculated spectra. The molecular orbitals (MOs) were visualized with Chimera. $^{59}$ 
For the comparative calculations performed on iron complexes, all parameters were the same as those for the ruthenium species, except that in this case the def2-TZVP basis set was employed. ${ }^{53}$

\section{RESULTS AND DISCUSSION}

3.1. Experimental and Calculated 4d-to-2p XES Spectra. The normalized 4d-to-2p XES spectra for the investigated series of $\mathrm{Ru}$ model complexes are shown in Figure 2, where the experimental spectra are located in the left panel and the DFT calculated spectra are shown in the right panel. All of the species bearing a $\mathrm{Ru}^{\mathrm{II}}$ center are characterized by an intense main peak at $\sim 2837 \mathrm{eV}$ (Table 1) and the

Table 1. Energies Extracted from the Features Present in the 4d-to-2p XES Spectra

\begin{tabular}{lcc}
\multicolumn{1}{c}{ complex } & main feature $(\mathrm{eV})$ & less intense features $(\mathrm{eV})$ \\
& $\mathrm{Ru}^{\mathrm{II}}$ Complexes \\
{$\left[\mathrm{Ru}^{\mathrm{II}}(\mathrm{tacn})_{2}\right]\left(\mathrm{PF}_{6}\right)_{2}$} & 2837.4 & 2833.2 \\
{$\left[\mathrm{Ru}^{\mathrm{II}}(\mathrm{DMAP})_{6}\right] \mathrm{Cl}_{2}$} & 2837.8 & \\
{$\left[\mathrm{Ru}^{\mathrm{II}}(\mathrm{bpy})_{3}\right]\left(\mathrm{PF}_{6}\right)_{2}$} & 2837.6 & $2831.2,2833.2$ \\
{$\left[\mathrm{Ru}^{\mathrm{II}}(\mathrm{CN})_{6}\right] \mathrm{K}_{4}$} & 2837.4 & $2830.9,2833.0$ \\
cis- $\mathrm{Ru}^{\mathrm{II}}(\mathrm{dmso})_{4} \mathrm{Cl}_{2}$ & 2837.2 & \\
& $\mathrm{Ru}^{\mathrm{III}}$ Complex \\
{$\left[\mathrm{Ru}^{\mathrm{III}}\left(\mathrm{NH}_{3}\right)_{6}\right] \mathrm{Cl}_{3}$} & $2837.1,2838.4$ & 2833.6 \\
\hline
\end{tabular}

presence of less intense bands at lower energies of $~ 2830-$ $2833 \mathrm{eV}$, which are variable in number and overall shape depending on the species. The XES spectra of $\left[\mathbf{R u}^{\mathrm{II}}(\mathbf{t a c n})_{2}\right]^{2+}$ and $\left[\mathbf{R u}^{\mathrm{II}}(\mathrm{DMAP})_{6}\right]^{2+}$ both consist of only one band at lower energy, although the spectra of $\left[\mathbf{R u}^{\mathrm{II}}(\mathbf{b} \mathbf{p y})_{3}\right]^{2+}$ and $\left[\mathbf{R u}^{\mathrm{II}}(\mathbf{C N})_{6}\right]^{2+}$ show two features in this energy range, particularly well-defined for the latter. Additionally, for the one-electron oxidized complex, $\left[\mathbf{R u}{ }^{\mathrm{III}}\left(\mathrm{NH}_{3}\right)_{6}\right]^{3+}$, the main peak splits into two, separated by $\sim 1.3 \mathrm{eV}$, whereas the band at lower energies shifts up in energy (by $\sim 0.4$ to $0.6 \mathrm{eV}$ ) relative to the $\mathrm{Ru}^{\mathrm{II}}$ complexes. To better understand the origins of the observed features, DFT calculations were utilized to calculate the spectra (Figure 2B,D). The calculated spectra are in good agreement with the experimental data and reproduce the general trends in both energy and intensity distributions. This thus allows us to use the computations to obtain further insight into the origins of the observed spectral features. In the sections that follow, we use a stepwise approach to provide a pedagogical deconvolution of the spectra.

We note that the following discussion focuses on a simple one-electron picture that can be interpreted with the aid of DFT calculations. This approach is sufficient for analyzing and assigning the main features of the XES spectra, as previously demonstrated for 3d TMs. ${ }^{31-35,37-40,60}$ It should be considered, however, that the calculations do not capture the weak satellite features above $\sim 2840 \mathrm{eV}$ (Figure 2). These features likely arise from multielectron excitations, which have a higher probability due to the employed incident excitation energies, which are well above the $2 \mathrm{p}$ ionization threshold. We refer the interested reader to references 61-64 for a more detailed discussion of multielectron excitations.

3.2. Influence of the Ligand Framework. To understand the influence of the ligands on the $\mathrm{Ru} 4 \mathrm{~d}$-to-2p XES spectra, it is useful to begin by calculating the 4d-to-2p XES of a hypothetical singlet $(\mathrm{S}=0) \mathrm{Ru}^{2+}$ atom in the absence of any ligands (Figure 3 ). In this case, only a single feature at $\sim 2838$ $\mathrm{eV}$ is observed in the XES spectrum, which corresponds to

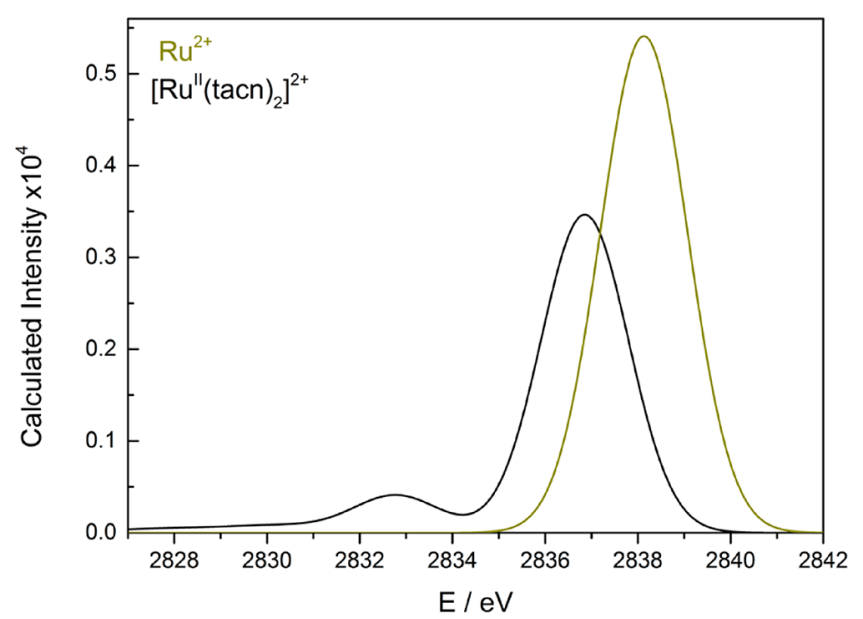

Figure 3. DFT calculated 4d-to-2p XES spectra for $\mathrm{Ru}^{2+}(\mathrm{S}=0)$ (dark yellow) and $\left[\mathbf{R u}^{\mathrm{II}}(\mathbf{t a c n})_{2}\right]^{2+}$ (black). The spectra are not normalized.

dipole-allowed transitions from the filled $\mathrm{Ru} 4 \mathrm{~d}$ orbitals to the $2 \mathrm{p}$ core hole.

Upon adding the $\sigma$-only donating tacn ligands, one observes a main feature at $\sim 2837 \mathrm{eV}$ and a new feature at $\sim 2833 \mathrm{eV}$. The main feature corresponds to transitions from the filled $t_{2 \mathrm{~g}}$ orbitals of $\left[\mathbf{R u}^{\mathrm{II}}(\operatorname{tacn})_{2}\right]^{2+}$ to the $2 \mathrm{p}$ core hole, as was the case for the isolated $\mathrm{Ru}^{2+}$ atom. However, both the energy and the intensity of this feature have decreased. The loss of intensity reflects a decrease in the percent of $4 \mathrm{~d}$ character in the donor $t_{2 g}$ orbitals, which has been reduced from $100 \%$ in the isolated $\mathrm{Ru}^{2+}$ atom to $\sim 85-91 \%$ in $\left[\mathbf{R u}^{\mathrm{II}}(\operatorname{tacn})_{2}\right]^{2+}$ due to covalent mixing with the ligands. This is an interesting observation for a $\sigma$-only donor such as tacn, where generally the $t_{2 g}$ covalency is assumed to be negligibly small ${ }^{65,66}$ due to the fact that the metal $t_{2 g}$ orbitals are nonbonding with the ligand orbitals in rigorous $O_{h}$ symmetry. The $\sim 6-9 \%$ tacn contribution to the filled $t_{2 g}$ orbitals thus reflects the mixing that becomes allowed due to deviations from ideal symmetry. The decrease in the energy of the $\sim 2837 \mathrm{eV}$ feature results from the net decrease in the effective charge on $\mathrm{Ru}$ upon complex formation, which destabilizes the $2 \mathrm{p}$ core orbital to a greater extent than the $4 \mathrm{~d}$ orbitals, resulting in a transition at lower energy. This is observable by inspection of the respective energies of the $2 p$ and $4 \mathrm{~d}$ orbitals for both considered systems. Whereas upon coordination the $2 \mathrm{p}$ orbitals are destabilized at $\sim 8.8 \mathrm{eV}$ due to the presence of the new point charges of the ligand environment, the $4 \mathrm{~d}$ orbitals show, on average, a destabilization of only $\sim 6.4 \mathrm{eV}$ upon coordination.

Finally, the transition at $\sim 2833 \mathrm{eV}$ may be assigned as transitions arising from filled tacn orbitals, which $\sigma$-interact with the empty set of $\mathrm{Ru} \mathrm{e}_{\mathrm{g}}$ orbitals. Hence, the intensity of this feature reflects the extent of $\mathrm{Ru} 4 \mathrm{~d}$ character in the filled tacn orbitals, which amounts to $\sim 20 \%$. These findings are also illustrated qualitatively in the MO diagram in Figure 4. Thus these results highlight that 4d-to-2p XES simultaneously probes both filled-metal- and filled-ligand-based orbitals. Because the selection rule is based on a dipole-allowed d-to$\mathrm{p}$ transition, these spectra provide a far more direct probe of metal-ligand bonding than valence-to-1s (or VtC) XES, where the intensity mechanism is derived from dipole-allowed p-to-s transitions and hence in most cases provides no direct information on the mixing of metal $n$ d orbitals with the ligands. ${ }^{32}$ 

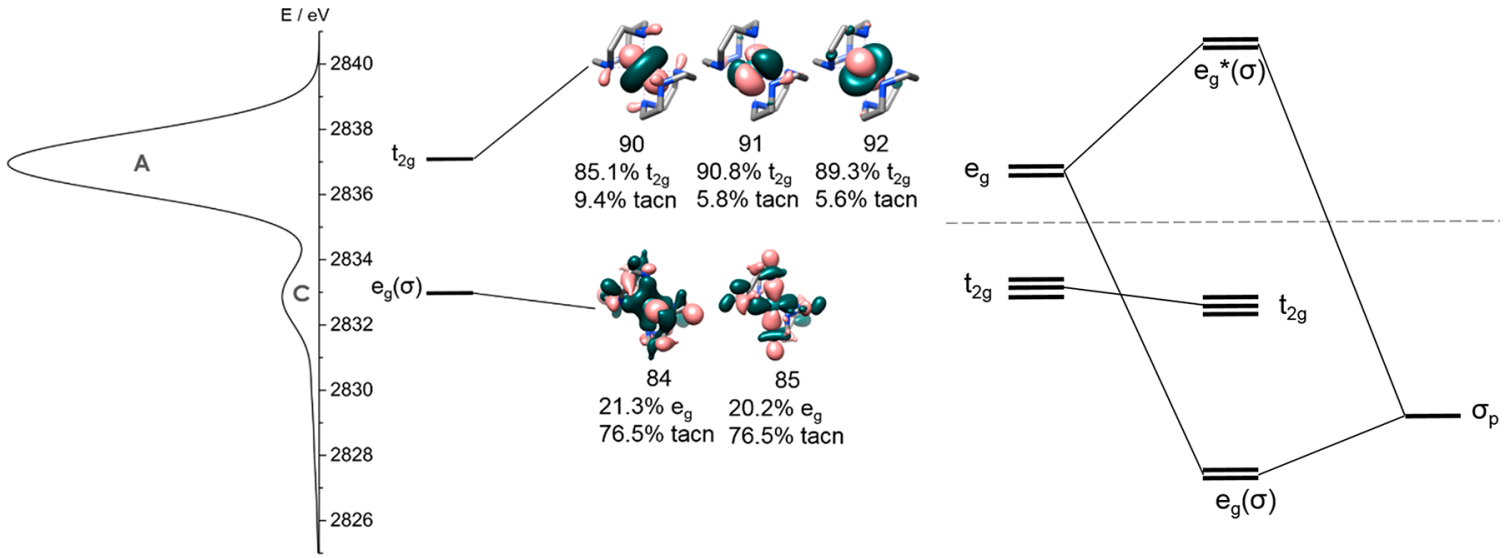

Figure 4. Molecular orbital analysis derived from the orbital origin of the bands (left). Qualitative molecular orbital diagram for $\left[\mathbf{R u}^{\mathrm{II}}(\operatorname{tacn})_{2}\right]^{2+}$ (right).

To more quantitatively understand the intensity mechanism of the observed $\mathrm{Ru} 4 \mathrm{~d}$-to-2 $\mathrm{p}$ spectral features for a $\sigma$-only donor ligand, we have also performed a series of hypothetical calculations in which the $\mathrm{Ru}-\mathrm{N}(\operatorname{tacn})$ bond distance is systematically varied through the symmetric breathing vibrational mode of the species (Figure 5).

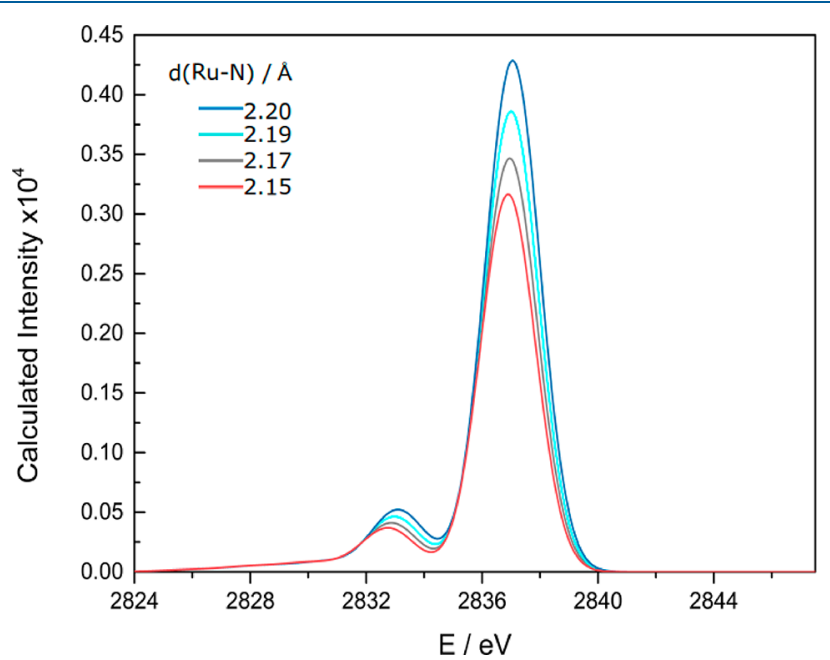

Figure 5. Calculated spectra for $\left[\mathrm{Ru}^{\mathrm{II}}(\operatorname{tacn})_{2}\right]^{2+}$ and structures obtained along its symmetric breathing vibrational mode, drawing the ligand environment closer to and further away from the metal. The $\mathrm{Ru}-\mathrm{N}$ average bond length is shown for each structure, being $2.17 \AA$ for the relaxed optimized structure. The spectra are not normalized.

The intensity of both features changes upon the variation of the $\mathrm{Ru}$-ligand distances. In particular, as the ligand is drawn away from the metallic center along its symmetric breathing vibrational mode, the intensity of the spectrum increases. This reflects the loss of covalent mixing of the metallic orbitals with the ligands, slightly increasing the $4 \mathrm{~d}$ character in the MOs that generate the transitions. As a result, the features gain intensity, showing that the $4 \mathrm{~d}$ character in the originating MOs drives the intensity mechanism of the features. It should be noted that the 4d-to-2p XES spectra are rather sensitive to the average $\mathrm{Ru}-\mathrm{N}$ bond length, with the intensity of the spectra increasing $23 \%$ over only a $1.4 \%$ increase in bond length and decreasing $9 \%$ over a $0.9 \%$ decrease in bond length. Additionally, although more clear in the $\sigma$-bonding $\mathrm{e}_{\mathrm{g}}(\sigma)$ feature, both features show a shift in energy to higher values upon elongation of the metal-ligand bond lengths. This behavior arises from the destabilization of the contributing MOs upon the loss of covalent mixing with ligand-based orbitals.

Having analyzed the pure $\sigma$-donor ligand case, a more complicated case can be tackled, where both $\sigma$ and $\pi$ contributions need to be considered. In this respect, a known $\sigma$ - and $\pi$-donating ligand is employed: DMAP, ${ }^{44}$ affording the octahedral $\left[\text { RuII }(\text { DMAP })_{6}\right]^{2+}$ species. The 4d-to$2 \mathrm{p}$ experimental XES spectrum of this species (Figure 2A) shares, in principle, the characteristics of the spectrum of $\left[\mathrm{Ru}^{\mathrm{II}}(\operatorname{tacn})_{2}\right]^{2+}$. In the same way as previously done, the origin of the features can be analyzed in combination with DFT calculations (Figure 6). From a closer analysis of the DFTcalculated spectrum, two components in the main feature can be detected, labeled A and B in Figure 6 (top).

The calculation shows that the main feature arises from $t_{2 g}$ orbitals, which are now partially mixed with $\pi$ orbitals of the DMAP ligands, originating two combinations: bonding and antibonding. The highest energy MOs arise from the antibonding $t_{2 g}-\pi(D M A P)$ combination, and at deeper binding energy (by $\sim 1.3 \mathrm{eV}$ ), the bonding combination appears. The two features are, however, not resolvable within the experimental resolution. Additionally, at lower energies and with less intensity, the ligand-based $\mathrm{e}_{\mathrm{g}}(\sigma)$ bonding interaction, originating from the mixing of $\mathrm{Ru} 4 \mathrm{~d}_{\mathrm{g}}$ and $\sigma$ (DMAP) orbitals, is observed.

In contrast with the previously analyzed spectra, the spectrum of $\left[\mathrm{Ru}^{\mathrm{II}}(\mathrm{CN})_{6}\right]^{4-}$ shows two distinct features at lower energies (Table 1). Owing to the diatomic nature of the ligands, the complexity of the spectrum increases. With the aid of DFT calculations, the origin of the observed features can be interpreted. The main feature arises from $t_{2 g}$ orbitals that appear to be antibonding or nonbonding (Figure 7), in contrast with the classical picture of $\mathrm{CN}^{-}$as a $\pi$-acceptor. With less intensity and lower energy, feature $B$ is found to be composed of two components: a $\sigma$-bonding interaction of $\mathrm{e}_{\mathrm{g}}$ orbitals with $\sigma\left(\mathrm{CN}^{-}\right)$orbitals (B1) and a $\pi$-bonding interaction of $t_{2 g}$ and $\pi\left(\mathrm{CN}^{-}\right)$orbitals (B2). At lower energies than $\mathrm{B}$, feature $\mathrm{C}$ originates from a $\sigma$-bonding interaction of $\mathrm{e}_{\mathrm{g}}$ orbitals with $\sigma\left(\mathrm{CN}^{-}\right)$orbitals.

As previously noted, the resulting MO diagram appears to contradict the traditional bonding picture, where cyanide is considered to be a strong $\pi$-acceptor ligand. In general, it is expected that the metal $t_{2 \mathrm{~g}}$ orbitals interact with the $\mathrm{CN}^{-}$via a 

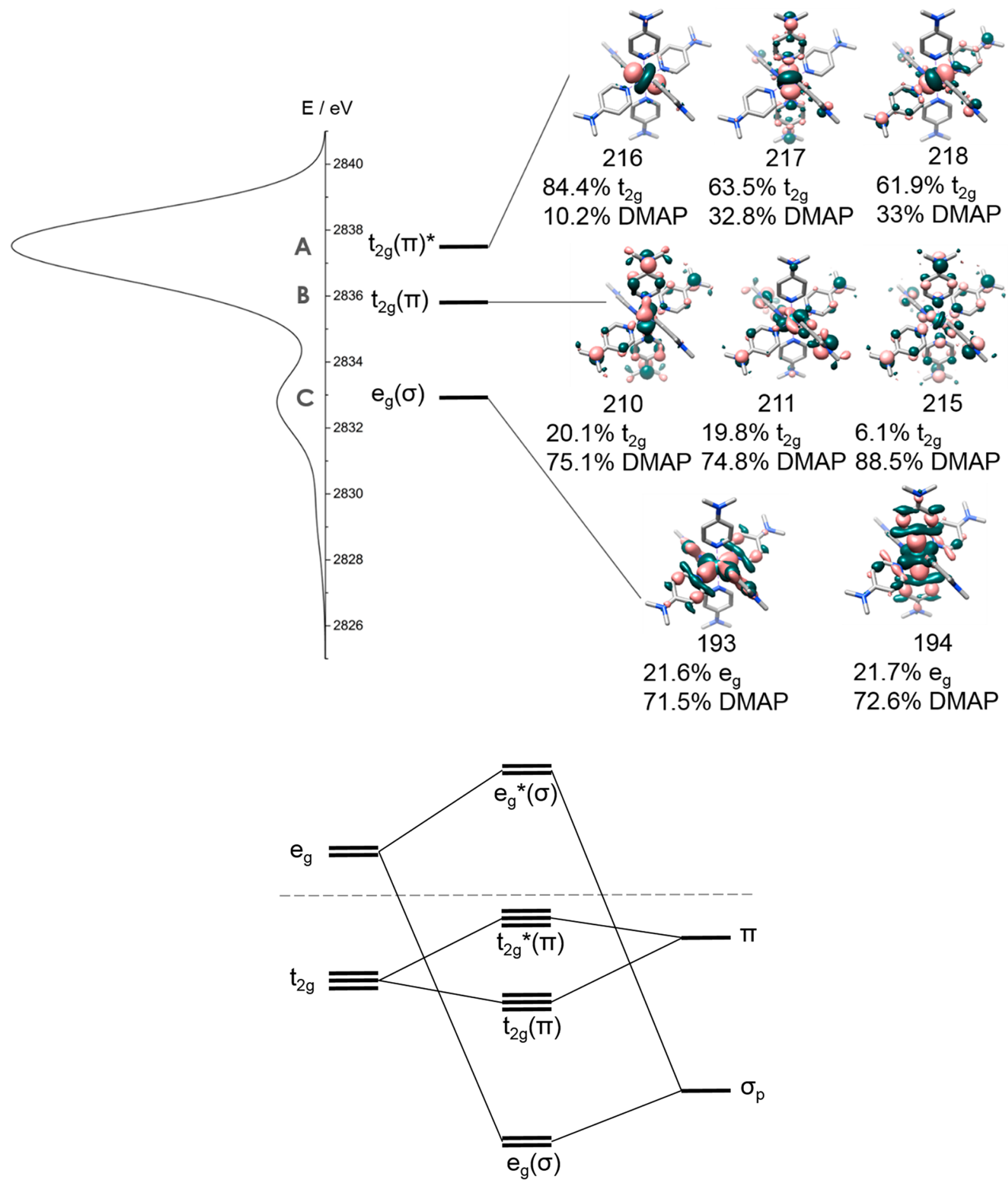

Figure 6. Molecular orbital analysis derived from the orbital origin of the bands (top). Qualitative molecular orbital diagram for $\left[\text { Ru(DMAP) }{ }_{6}\right]^{2+}$ (bottom).

strong $\pi$-back-bonding interaction, which is not present in the calculated MOs (Figure 7). If a stepwise construction of the diagram is considered, then, first, only the $\pi$ interactions can be addressed (Figure 8). Both $\pi\left(\mathrm{CN}^{-}\right)$and $\pi^{*}\left(\mathrm{CN}^{-}\right)$can interact with the filled $t_{2 g}$ orbitals, affording a bonding combination, which is mainly $\pi\left(\mathrm{CN}^{-}\right)$in character, an antibonding combination, which is mainly $\pi^{*}\left(\mathrm{CN}^{-}\right)$in character, and an intermediate in energy combination, which is mainly $t_{2 g}$ in character. Because of the interplay of the energies of these different orbitals, the $\mathrm{CN}^{-}$can be considered as having more $\pi$-acceptor or $\pi$-donor character, and in this case, the $t_{2 g}$ orbitals are effectively nonbonding, with some mixing with $\mathrm{CN}^{-}$orbitals, where the $\pi$-donor character predominates. We note that the non- $\pi$-acceptor character of $\mathrm{CN}^{-}$has already been reported for other hexacyanide metal complexes. ${ }^{42}$ In addition to the $\pi$ interactions, because of the $\sigma$-donor character of $\mathrm{CN}^{-}$, there is also mixing of the $\mathrm{e}_{\mathrm{g}}$ orbitals with $\mathrm{CN}^{-}$ orbitals with the appropriate symmetry, namely, $\sigma^{*}(2 s-2 s)$ and $\sigma(2 \mathrm{p}-2 \mathrm{p})$, originating three $\mathrm{e}_{\mathrm{g}}(\sigma)$ MOs.

The last complex to analyze in the series of $\mathrm{Ru}^{\mathrm{II}}$ species is $\left[\mathbf{R u} \mathbf{u}^{\text {II }}(\mathbf{b p y})_{3}\right]^{2+}$ (Figure $\left.2 \mathrm{~A}, \mathrm{~B}\right)$. The spectrum of this species is similar in the number of features and energies to that of 


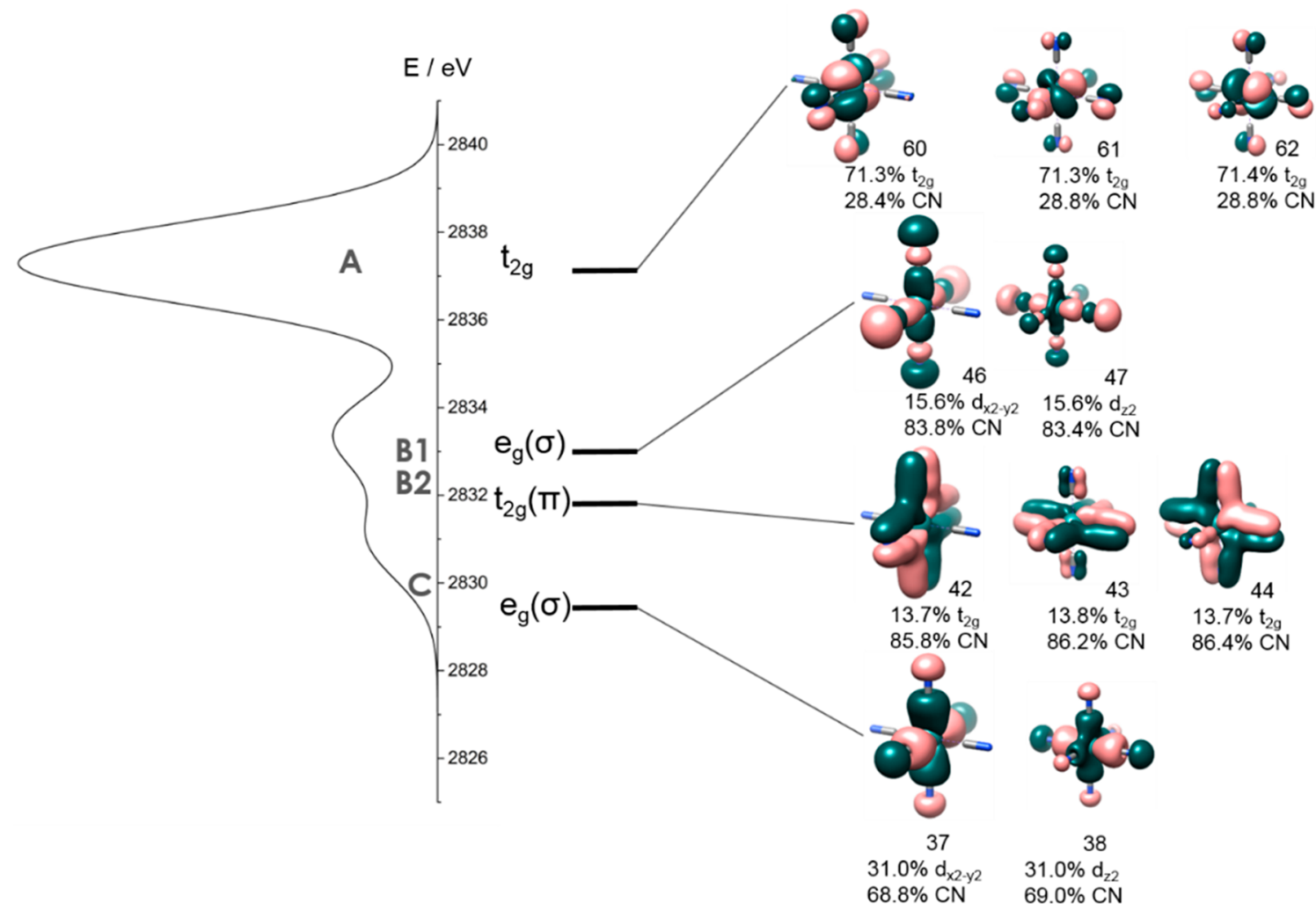

Figure 7. Molecular orbital analysis derived from the orbital origin of the bands for $\left[\operatorname{Ru}^{\mathrm{II}}(\mathbf{C N})_{6}\right]^{4-}$.
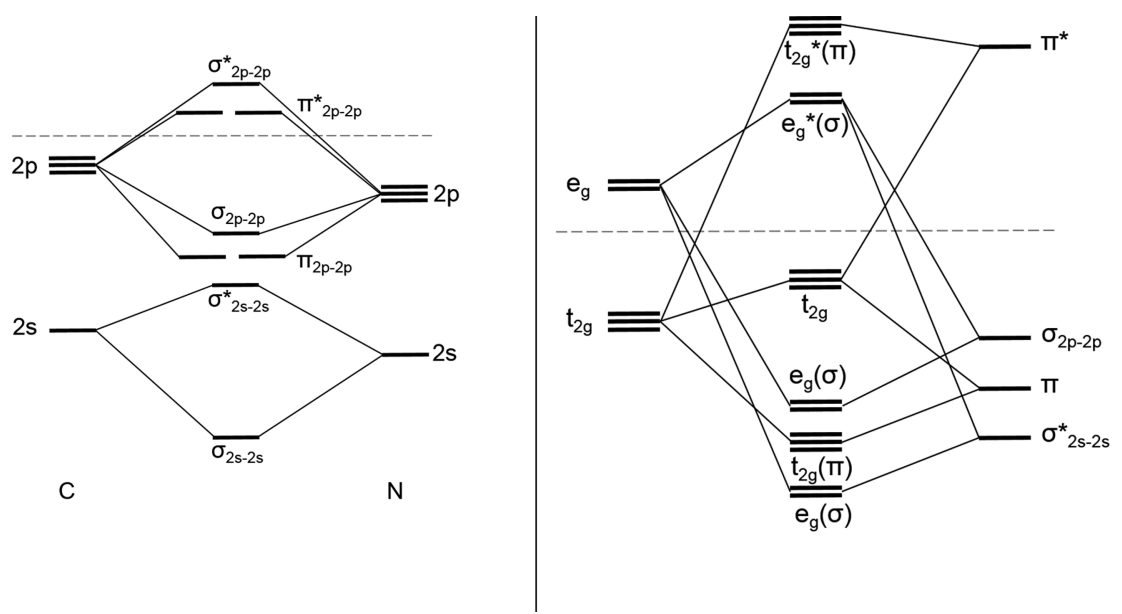

Figure 8. Qualitative molecular orbital diagram for $\mathrm{CN}^{-}$(left) and $\left[\mathrm{Ru}^{\mathrm{II}}(\mathrm{CN})_{6}\right]^{4-}$ (right).

$\left[\mathbf{R u}^{\mathrm{II}}(\mathbf{C N})_{6}\right]^{4-}$. The relevant point group to consider in this case is $D_{3}$, where, first, the octahedral symmetry is lifted and a small trigonal perturbation appears. ${ }^{67}$ In this point group, the $4 \mathrm{~d}$ orbitals split into one $\mathrm{a}_{1}$ and two e sets. The DFT analysis shows that the main feature of the spectrum originates from $a_{1}$ and e orbitals, which are mostly $4 \mathrm{~d}$ in character (Figure 9). The lower energy features comes from different MOs from the e set that possess $\mathrm{Ru} 4 \mathrm{~d}$ character and both $\pi$ and $\sigma$ mixing with ligand orbitals.

The derived MO diagram for $\left[\mathbf{R u}^{\mathrm{II}}(\mathbf{b p y})_{3}\right]^{2+}$ is in agreement with previously reported diagrams. ${ }^{67,68}$

3.3. Oxidation State. In addition to the series of $\mathrm{Ru}^{\mathrm{II}}$ species, a one-electron oxidized complex, $\left[\mathrm{Ru}^{\mathrm{III}}\left(\mathrm{NH}_{3}\right)_{6}\right]^{3+}$, was studied to assess the influence of the oxidation state of the photoabsorber in the L-emission lines. Because of the nature of the amino ligands, a similar electronic structure, and therefore similar spectral features, is expected for $\left[\mathrm{Ru}^{\mathrm{III}}\left(\mathrm{NH}_{3}\right)_{6}\right]^{3+}$ and $\left[\mathbf{R u}^{\mathrm{II}}(\mathbf{t a c n})_{2}\right]^{2+}$, analyzed previously, since they both possess a $\sigma$-only ligand environment. As shown in Figure 2C and Table 1 , the spectrum of $\left[\mathbf{R u}^{\mathrm{III}}\left(\mathrm{NH}_{3}\right)_{6}\right]^{3+}$ is composed of a main feature at $\sim 2838 \mathrm{eV}$ and a less intense feature at $\sim 2834 \mathrm{eV}$. However, the spectrum of $\left[\mathrm{Ru}^{\mathrm{III}}\left(\mathrm{NH}_{3}\right)_{6}\right]^{3+}$ is characterized by broadening of the main feature, arising from transitions from the filled $t_{2 g}$ orbitals, which splits into two components at 2837.1 and $2838.4 \mathrm{eV}$. This difference can be interpreted with the aid of DFT calculations (Figure 2 and Figure S1).

The overlay of the experimental and calculated spectra for $\left[\mathbf{R u}^{\text {III }}\left(\mathrm{NH}_{3}\right)_{6}\right]^{3+}$ in Figure S1 shows a correlation between the broadening of the experimental feature and the formation of two distinct groups of calculated transitions separated by $\sim 1.3$ 


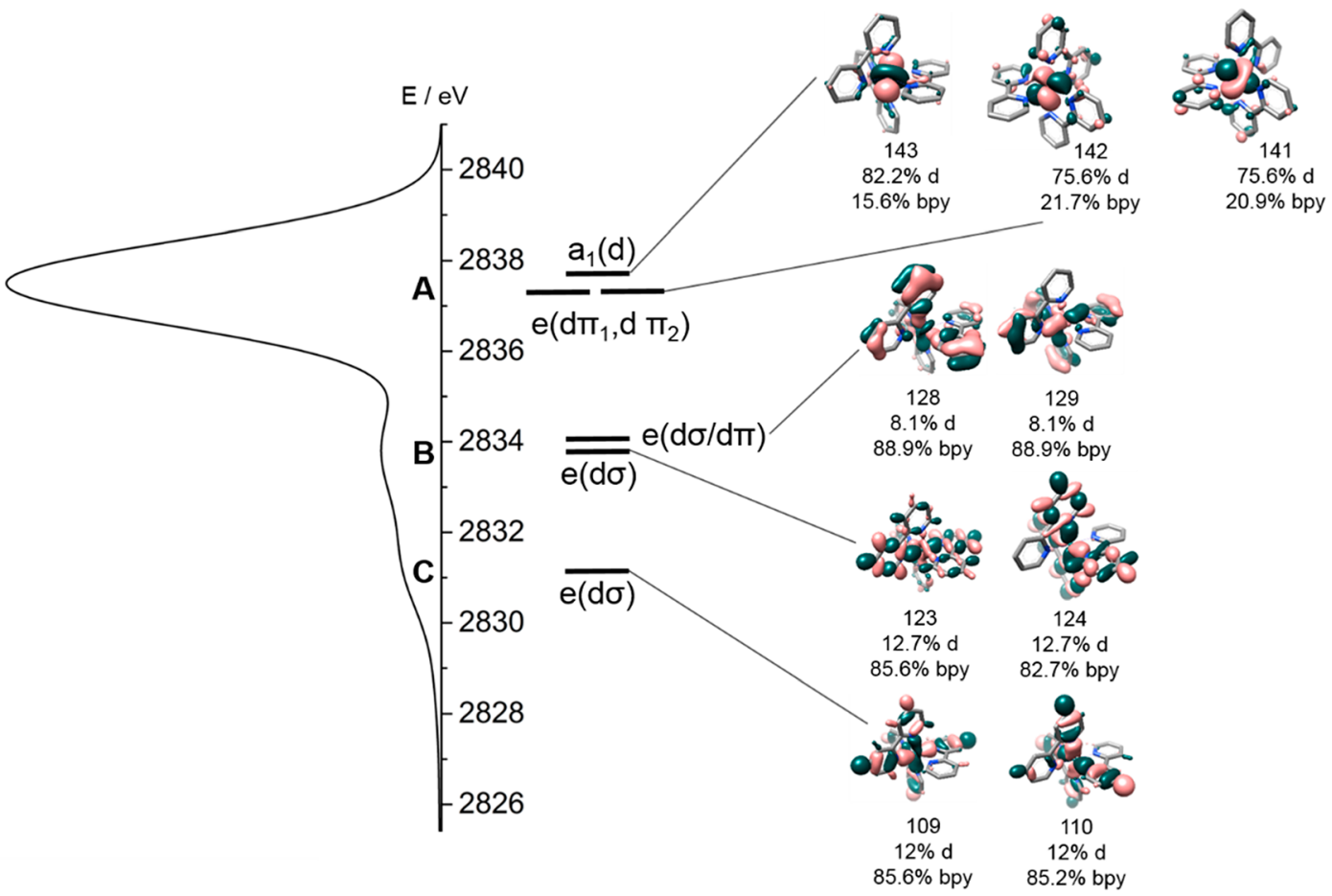

Figure 9. Molecular orbital analysis derived from the orbital origin of the bands for $\left[\mathrm{Ru}^{\mathrm{II}}(\mathbf{b p y})_{3}\right]^{2+}$.

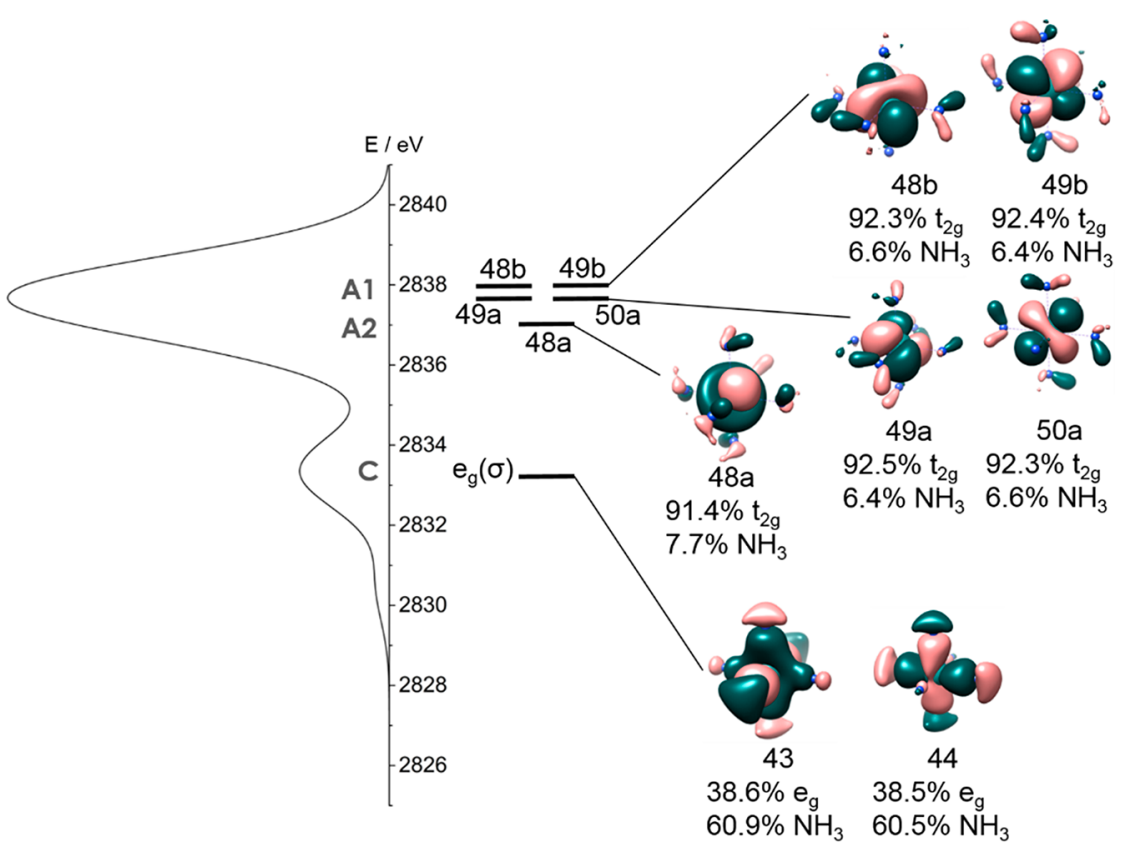

Figure 10. Molecular orbital analysis derived from the orbital origin of the bands for $\left[\mathrm{Ru}^{\mathrm{III}}\left(\mathrm{NH}_{3}\right)_{6}\right]^{3+}$.

$\mathrm{eV}$. Furthermore, Voigt deconvolution of the spectrum clearly shows two components in the main peak (Figure S6), whereas only one is present for the studied $\mathrm{Ru}^{\mathrm{II}}$ species (Figures $\mathrm{S} 2-$ S5). To rationalize these differences, a closer inspection of the orbital origin of the features is required. Figure 10 shows the MOs involved in each region of the spectrum.

For the open-shell $4 d^{5}\left[\mathbf{R u}^{\text {III }}\left(\mathrm{NH}_{3}\right)_{6}\right]^{3+}$ species, the $t_{2 g}$ orbitals are partially filled. Unlike the previously explored low-spin $d^{6}$ configurations, in the case of the open-shell lowspin $\mathrm{d}^{5}$ configuration, there is significant spin-polarization contribution that accounts for the separation of the valence orbitals into separate spin orbitals with different spatial densities $\alpha$ and $\beta$. As a result, different emission channels contribute to the spectrum, and the energy separation between them accounts for the broadening of the spectrum. Although this does not accurately capture the true multiplet structure, previous studies have shown that a simple DFT approach can roughly approximate the expected splitting. ${ }^{69}$ What becomes clear from Figure 10 and the energy ordering of the spin orbitals is that the emission from the spin orbital 48 a generates the $2837.1 \mathrm{eV}$ component of the main feature, whereas the transitions from the other four filled $t_{2 g}$ spin orbitals (48a, 49a, $49 \mathrm{~b}$, and 50a) generate a group of transitions closer in energy that give rise to the $2838.4 \mathrm{eV}$ feature. As a result, the 


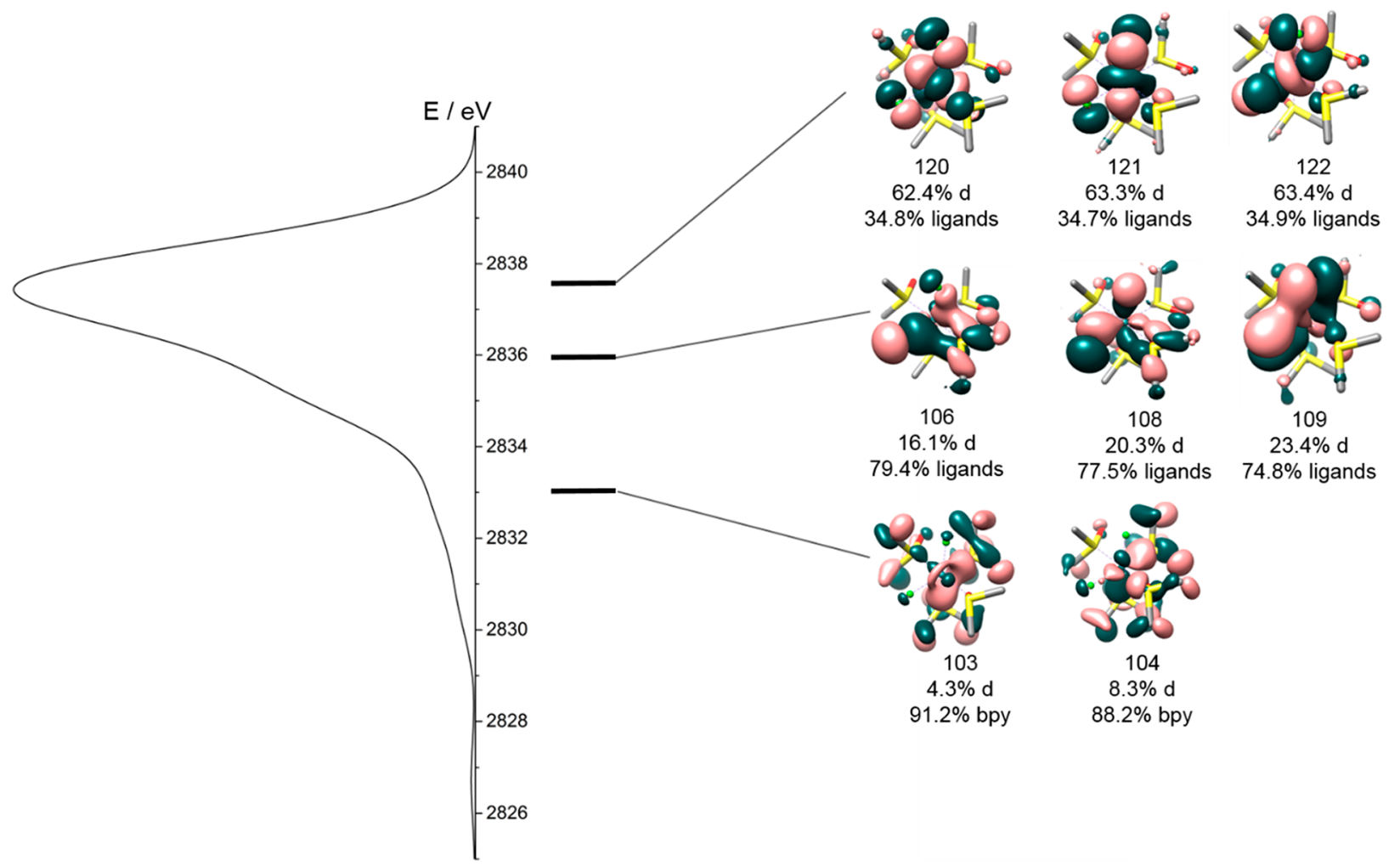

Figure 11. Orbital origin of the bands for cis-[ $\left.\mathrm{Ru}^{\mathrm{II}}(\mathrm{dmso})_{4} \mathrm{Cl}_{2}\right]$.

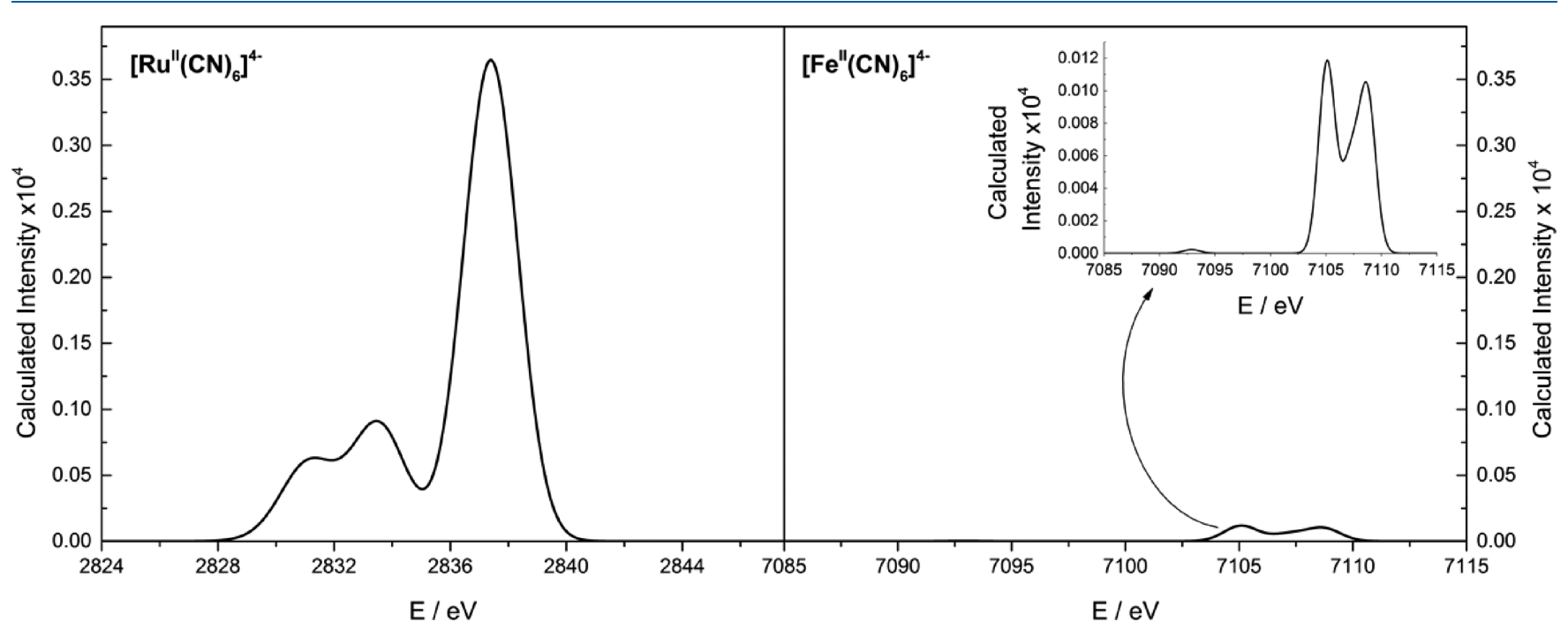

Figure 12. Comparison of intensities of the calculated spectra of $\left[\mathrm{Ru}^{\mathrm{II}}(\mathrm{CN})_{6}\right]^{4-}($ left $)$ and $\left[\mathrm{Fe}^{\mathrm{II}}(\mathrm{CN})_{6}\right]^{4-}$ (right).

broadening of the main peak reduces the intensity of the feature, changing the intensity ratio between the main feature $\mathrm{A}$ and the less intense $\mathrm{C}$, which arises from the bonding $\sigma$ combination of the $\mathrm{e}_{\mathrm{g}}$ and $\sigma$ orbitals from the ligands. Furthermore, the $d^{5}$ configuration, in comparison with the $d^{6}$ configuration, possesses one fewer allowed emission event, which is responsible for an overall reduction of the intensity of feature $\mathrm{A}$. The oxidation state influence in the $\mathrm{A} / \mathrm{C}$ intensity ratio can also be clearly distinguished in the overlap of the DFT calculated spectra for $\left[\mathbf{R u}^{\mathrm{III}}\left(\mathrm{NH}_{3}\right)_{6}\right]^{3+}$ and its reduced analog $\left[\mathbf{R u}^{\mathrm{II}}\left(\mathrm{NH}_{3}\right)_{6}\right]^{2+}$ (Figure S7).

3.4. Site Symmetry. For the (pseudo) octahedral or symmetric species analyzed here so far, the electronic structure of the complexes can be rationalized in terms of MO diagrams with the combination of experimental XES L-emission lines and DFT calculated spectra. Regardless of the oxidation state of the photoabsorber or the nature of the bound ligands, the spectra consist of a main feature (originating from the filled $t_{2 g}$ orbitals) and one or two less intense features $\sim 4 \mathrm{eV}$ lower in energy. Nevertheless, this is not the case anymore for the asymmetric cis- $\left[\mathbf{R u}{ }^{\mathrm{II}}(\mathbf{d m s o})_{4} \mathbf{C l}_{2}\right]$ (Figure $2 \mathrm{C}$ ). The loss of symmetry and the inclusion of different ligating atoms in the ligand environment have strong effects in the spectral profile of the species. The enhanced mixing of orbitals results in less defined features. The main feature and those originating from mostly ligand-based orbitals overlap, resulting in a broad 
feature with less structure. The main orbitals from which the emission lines originate are shown in Figure 11.

3.5. Comparison with VtC 1s. The $\mathrm{Ru} 4 \mathrm{~d}$-to-2p XES allows the unique possibility to simultaneously probe both metal- and ligand-based orbitals. This is in contrast with the better known valence-to-1s (VtC) XES, which dominantly originates from metal $\mathrm{p}$ character mixing into ligand-based orbitals. Whereas collecting VtC XES can be challenging due to the weakness of the lines, the dipole-allowed nature of the $4 d$-to-2p XES lines greatly enhances the observed spectral intensities. A comparison of calculated emission spectra (Figure 12) shows that the 4d-to-2p spectrum for $\left[\mathrm{Ru}^{\mathrm{II}}(\mathrm{CN})_{6}\right]^{4-}$ presents $\sim 30$ times increased intensity with respect to the $\mathrm{VtC}$ spectrum of $\left[\mathrm{Fe}^{\mathrm{II}}(\mathrm{CN})_{6}\right]^{4-}$.

Hence, 4d-to-2p XES spectroscopy holds promise as a unique tool to investigate $\mathrm{Ru}$ species. Of particular interest is the possibility of studying Ru-based catalysts, widely spread in diverse areas of chemistry. $5,6,70$

\section{CONCLUSIONS}

4d-to-2p XES is shown to be a promising tool to achieve detailed insight into the electronic structure of $\mathrm{Ru}$ complexes. Because of the dipole-allowed nature of the lines, intense emission lines arise. The spectra of symmetric octahedral species consist of a main feature at $\sim 2837 \mathrm{eV}$, originating from the filled $t_{2 g}$ orbitals, and two or fewer less intense feature(s) at a lower energy of $\sim 2833 \mathrm{eV}$. Whereas the main feature is characteristic of the oxidation state of the metal center, the features at lower energies and lower intensity are dependent on the ligand identity. DFT calculations complemented the analysis and allowed for detailed insight into the electronic structure origins of the observed spectral features. A unique characteristic of $4 \mathrm{~d}$-to- $2 \mathrm{p}$ XES is the ability to observe dipoleallowed transitions arising from both filled-np-ligand- and filled-4d-metal-based orbitals. The energies and intensities of the features are a direct reflection of the strength of metalligand bonding via covalency. As such, 4d-to-2p XES should serve as a very useful electronic structure probe for $\mathrm{Ru}$ and other $4 \mathrm{~d}$ TMs.

\section{ASSOCIATED CONTENT}

\section{SI Supporting Information}

The Supporting Information is available free of charge at https://pubs.acs.org/doi/10.1021/acs.inorgchem.0c00663.

Additional experimental and computational information details (PDF)

\section{AUTHOR INFORMATION}

\section{Corresponding Author}

Serena DeBeer - Max Planck Institute for Chemical Energy Conversion, 45470 Mülheim an der Ruhr, Germany; ๑ orcid.org/0000-0002-5196-3400; Email: serena.debeer@ cec.mpg.de

\section{Authors}

Natalia Levin - Max Planck Institute for Chemical Energy Conversion, 45470 Mülheim an der Ruhr, Germany; (1) orcid.org/0000-0001-9567-8604

Sergey Peredkov - Max Planck Institute for Chemical Energy Conversion, 45470 Mülheim an der Ruhr, Germany;

(1) orcid.org/0000-0002-5816-9015
Thomas Weyhermüller - Max Planck Institute for Chemical Energy Conversion, 45470 Mülheim an der Ruhr, Germany; (1) orcid.org/0000-0002-0399-7999

Olaf Rüdiger - Max Planck Institute for Chemical Energy Conversion, 45470 Mülheim an der Ruhr, Germany; (1) orcid.org/0000-0002-5148-9083

Nilson B. Pereira - Max Planck Institute for Chemical Energy Conversion, 45470 Mülheim an der Ruhr, Germany; (1) orcid.org/0000-0002-0777-3423

Daniel Grötzsch - Institut für Optik und Atomare Physik (IOAP), TU-Berlin, 10623 Berlin, Germany

Aleksandr Kalinko - DESY Photon Science, 22603 Hamburg, Germany; Universität Paderborn, 33098 Paderborn, Germany; (1) orcid.org/0000-0002-0615-4735

Complete contact information is available at: https://pubs.acs.org/10.1021/acs.inorgchem.0c00663

\section{Funding}

The Max Planck Society is acknowledged for funding. Notes

The authors declare no competing financial interest.

\section{ACKNOWLEDGMENTS}

We thank the Deutsche Elektronen-Synchrotron DESY for beam time at PETRA III, beamline P64 under proposal I20180155 as well as the Helmholtz-Zentrum Berlin for beam time at the Energy Materials In-Situ Laboratory Berlin (EMIL), beamline PINK. Minmin Chen is acknowledged for her support during the collection of the data at DESY and Dr. Anselm Hahn, Dr. Dimitrios Manganas and Dr. Mihail Atanasov are acknowledged for helpful discussions regarding MO theory.

\section{REFERENCES}

(1) O’Regan, B.; Grätzel, M. A low-cost, high-efficiency solar cell based on dye-sensitized colloidal $\mathrm{TiO} 2$ films. Nature 1991, 353 (6346), 737-740.

(2) Damrauer, N. H.; Cerullo, G.; Yeh, A.; Boussie, T. R.; Shank, C. V.; McCusker, J. K. Femtosecond Dynamics of Excited-State Evolution in $\left[\mathrm{Ru}(\mathrm{bpy})_{3}\right]^{2+}$. Science 1997, 275 (5296), 54-57.

(3) Gersten, S. W.; Samuels, G. J.; Meyer, T. J. Catalytic oxidation of water by an oxo-bridged ruthenium dimer. J. Am. Chem. Soc. 1982, 104 (14), 4029-4030.

(4) Kärkäs, M. D.; Verho, O.; Johnston, E. V.; Åkermark, B. Artificial Photosynthesis: Molecular Systems for Catalytic Water Oxidation. Chem. Rev. 2014, 114 (24), 11863-12001.

(5) Ogba, O. M.; Warner, N. C.; O'Leary, D. J.; Grubbs, R. H. Recent advances in ruthenium-based olefin metathesis. Chem. Soc. Rev. 2018, 47 (12), 4510-4544.

(6) Dub, P. A.; Gordon, J. C. The role of the metal-bound N-H functionality in Noyori-type molecular catalysts. Nature Reviews Chemistry 2018, 2 (12), 396-408.

(7) de Boer, T. R.; Mascharak, P. K. Recent Progress in Photoinduced NO Delivery with Designed Ruthenium Nitrosyl Complexes. $\mathrm{NO}_{x}$ Related Chemistry 2015, 67, 145-170.

(8) Levin, N.; Codesido, N. O.; Bill, E.; Weyhermüller, T.; Segantin Gaspari, A. P.; da Silva, R. S.; Olabe, J. A.; Slep, L. D. Structural, Spectroscopic, and Photochemical Investigation of an Octahedral NO-Releasing $\left\{\mathrm{RuNO}^{7}\right.$ Species. Inorg. Chem. 2016, 55 (16), 78087810.

(9) Bari, S. E.; Olabe, J. A.; Slep, L. D. Three Redox States of Metallonitrosyls in Aqueous Solution. Adv. Inorg. Chem. 2015, 67, 87-144.

(10) Levin, N.; Codesido, N. O.; Marcolongo, J. P.; Alborés, P.; Weyhermüller, T.; Olabe, J. A.; Slep, L. D. Remarkable Changes of the 
Acidity of Bound Nitroxyl (HNO) in the $\left[\mathrm{Ru}\left(\mathrm{Me}_{3}[9] \mathrm{aneN}_{3}\right)\left(\mathrm{L}^{2}\right)\right.$ $(\mathrm{NO})]^{\mathrm{n}+}$ Family $(\mathrm{n}=1-3)$. Systematic Structural and Chemical Exploration and Bioinorganic Chemistry Implications. Inorg. Chem. 2018, 57 (19), 12270-12281.

(11) Okamoto, K.; Miyawaki, J.; Nagai, K.; Matsumura, D.; Nojima, A.; Yokoyama, T.; Kondoh, H.; Ohta, T. Structural Study on Highly Oxidized States of a Water Oxidation Complex [ $\left.\mathrm{Ru}^{\text {III }}(\text { bpy })_{2}\left(\mathrm{H}_{2} \mathrm{O}\right)\right]_{2}(\mu \text {-O })^{4+}$ by Ruthenium K-Edge X-ray Absorption Fine Structure Spectroscopy. Inorg. Chem. 2003, 42 (26), 8682-8689. (12) Getty, K.; Delgado-Jaime, M. U.; Kennepohl, P. Assignment of pre-edge features in the $\mathrm{Ru} \mathrm{K}$-edge $\mathrm{X}$-ray absorption spectra of organometallic ruthenium complexes. Inorg. Chim. Acta 2008, 361 (4), 1059-1065.

(13) Planas, N.; Vigara, L.; Cady, C.; Miró, P.; Huang, P.; Hammarström, L.; Styring, S.; Leidel, N.; Dau, H.; Haumann, M.; Gagliardi, L.; Cramer, C. J.; Llobet, A. Electronic structure of oxidized complexes derived from cis-[Ru(II)(bpy $\left.)_{2}\left(\mathrm{H}_{2} \mathrm{O}\right)_{2}\right]^{2+}$ and Its Photoisomerization Mechanism. Inorg. Chem. 2011, 50 (21), 11134-42.

(14) Vigara, L.; Ertem, M. Z.; Planas, N.; Bozoglian, F.; Leidel, N.; Dau, H.; Haumann, M.; Gagliardi, L.; Cramer, C. J.; Llobet, A. Experimental and quantum chemical characterization of the water oxidation cycle catalysed by $\left[\mathrm{Ru}^{\mathrm{II}}(\mathrm{damp})(\mathrm{bpy})\left(\mathrm{H}_{2} \mathrm{O}\right)\right]^{2+}$. Chemical Science 2012, 3 (8), 2576-2576.

(15) Moonshiram, D.; Jurss, J. W.; Concepcion, J. J.; Zakharova, T.; Alperovich, I.; Meyer, T. J.; Pushkar, Y. Structure and electronic configurations of the intermediates of water oxidation in blue ruthenium dimer catalysis. J. Am. Chem. Soc. 2012, 134 (10), $4625-4636$.

(16) Pushkar, Y.; Moonshiram, D.; Purohit, V.; Yan, L.; Alperovich, I. Spectroscopic Analysis of Catalytic Water Oxidation by $\left[\mathrm{Ru}^{\mathrm{II}}\right.$ (bpy) (tpy) $\left.\mathrm{H}_{2} \mathrm{O}\right]^{2+}$ Suggests That $\mathrm{Ru}^{\mathrm{V}}=\mathrm{O}$ Is Not a Rate-Limiting Intermediate. J. Am. Chem. Soc. 2014, 136 (34), 11938-11945.

(17) Krause, M. O.; Oliver, J. H. Natural widths of atomic K and L levels, K $\alpha$ X-ray lines and several KLL Auger lines. J. Phys. Chem. Ref. Data 1979, 8 (2), 329-338.

(18) König, C. F. J.; Schildhauer, T. J.; Nachtegaal, M. Methane synthesis and sulfur removal over a Ru catalyst probed in situ with high sensitivity X-ray absorption spectroscopy. J. Catal. 2013, 305, 92-100.

(19) Pelliccione, C. J.; Timofeeva, E. V.; Katsoudas, J. P.; Segre, C. $\mathrm{U}$. In situ Ru K-edge X-ray absorption spectroscopy study of methanol oxidation mechanisms on model submonolayer $\mathrm{Ru}$ on $\mathrm{Pt}$ nanoparticle electrocatalyst. J. Phys. Chem. C 2013, 117 (37), 1890418912.

(20) Lebedev, D.; Pineda-Galvan, Y.; Tokimaru, Y.; Fedorov, A.; Kaeffer, N.; Copéret, C.; Pushkar, Y. The key $\mathrm{Ru}^{\mathrm{V}}=\mathrm{O}$ intermediate of site-isolated mononuclear water oxidation catalyst detected by in situ X-ray absorption spectroscopy. J. Am. Chem. Soc. 2018, 140, 451-458.

(21) Sham, T. K. X-ray Absorption Spectra of Ruthenium L Edges in $\mathrm{Ru}\left(\mathrm{NH}_{3}\right)_{6} \mathrm{Cl}_{3}$. J. Am. Chem. Soc. 1983, 105, 2269-2273.

(22) Harris, T. V.; Szilagyi, R. K.; McFarlane Holman, K. L. Electronic structural investigations of ruthenium compounds and anticancer prodrugs. JBIC, J. Biol. Inorg. Chem. 2009, 14 (6), 891898.

(23) Alperovich, I.; Smolentsev, G.; Moonshiram, D.; Jurss, J. W.; Concepcion, J. J.; Meyer, T. J.; Soldatov, A.; Pushkar, Y. Understanding the electronic structure of $4 \mathrm{~d}$ metal complexes: From molecular spinors to L-edge spectra of a di-Ru catalyst. J. Am. Chem. Soc. 2011, 133 (39), 15786-15794.

(24) Shearer, J.; Callan, P. E.; Masitas, C. A.; Grapperhaus, C. A. Influence of sequential thiolate oxidation on a nitrile hydratase mimic probed by multiedge X-ray absorption spectroscopy. Inorg. Chem. 2012, 51 (11), 6032-6045.

(25) Van Kuiken, B. E.; Valiev, M.; Daifuku, S. L.; Bannan, C.; Strader, M. L.; Cho, H.; Huse, N.; Schoenlein, R. W.; Govind, N.; Khalil, M. Simulating Ru $\mathrm{L}_{3}$-Edge $\mathrm{X}$ - ray Absorption Spectroscopy with Time- Dependent Density Functional Theory: Model Complexes and Electron Localization in Mixed-Valence Metal Dimers. J. Phys. Chem. A 2013, 117 (21), 4444-4454.
(26) Alperovich, I.; Moonshiram, D.; Concepcion, J. J.; Pushkar, Y. Electronic Structure Assessment: Combined Density Functional Theory Calculations and $\mathrm{Ru} \mathrm{L} \mathrm{L}_{2,3}$-Edge X-ray Absorption Near-Edge Spectroscopy of Water Oxidation Catalyst. J. Phys. Chem. C 2013, 117 (37), 18994-19001.

(27) Castillo, R. G., Henthorn, J. T., McGale, J., Maganas, D., DeBeer, S. K $\beta$ X-ray Emission Spectroscopic study of a second-row transition metal (Mo) and its application to nitrogenase related model complexes. Angew. Chem., Int. Ed., 2020, DOI: 10.1002/ ange.202003621.

(28) Pollock, C. J.; DeBeer, S. Insights into the Geometric and Electronic Structure of Transition Metal Centers from Valence-toCore X-ray Emission Spectroscopy. Acc. Chem. Res. 2015, 48 (11), 2967-2975.

(29) Kowalska, J.; DeBeer, S. The role of X-ray spectroscopy in understanding the geometric and electronic structure of nitrogenase. Biochim. Biophys. Acta, Mol. Cell Res. 2015, 1853 (6), 1406-1415.

(30) Doonan, C. J.; Zhang, L.; Young, C. G.; George, S. J.; Deb, A.; Bergmann, U.; George, G. N.; Cramer, S. P. High-resolution X-ray emission spectroscopy of molybdenum compounds. Inorg. Chem. 2005, 44 (8), 2579-2581.

(31) Lancaster, K. M.; Roemelt, M.; Ettenhuber, P.; Hu, Y.; Ribbe, M. W.; Neese, F.; Bergmann, U.; DeBeer, S. X-ray emission spectroscopy evidences a central carbon in the nitrogenase ironmolybdenum cofactor. Science 2011, 334 (6058), 974-977.

(32) Pollock, C. J.; DeBeer, S. Valence-to-core X-ray emission spectroscopy: A sensitive probe of the nature of a bound ligand. J. Am. Chem. Soc. 2011, 133 (14), 5594-5601.

(33) Delgado-Jaime, M. U.; DeBeer, S.; Bauer, M. Valence-to-core $\mathrm{X}$-ray emission spectroscopy of iron-carbonyl complexes: Implications for the examination of catalytic intermediates. Chem. - Eur. J. 2013, 19 (47), 15888-15897.

(34) Smolentsev, G.; Soldatov, A. V.; Messinger, J.; Merz, K.; Weyhermüller, T.; Bergmann, U.; Pushkar, Y.; Yano, J.; Yachandra, V. K.; Glatzel, P. X-ray emission spectroscopy to study ligand valence orbitals in Mn coordination complexes. J. Am. Chem. Soc. 2009, 131 (36), 13161-13167.

(35) Lassalle-Kaiser, B.; Boron, T. T.; Krewald, V.; Kern, J.; Beckwith, M. A.; Delgado-Jaime, M. U.; Schroeder, H.; Alonso-Mori, R.; Nordlund, D.; Weng, T. C.; Sokaras, D.; Neese, F.; Bergmann, U.; Yachandra, V. K.; DeBeer, S.; Pecoraro, V. L.; Yano, J. Experimental and computational $\mathrm{X}$-ray emission spectroscopy as a direct probe of protonation states in oxo-bridged MnIV dimers relevant to redoxactive metalloproteins. Inorg. Chem. 2013, 52 (22), 12915-12922.

(36) Krewald, V.; Lassalle-Kaiser, B.; Boron, T. T.; Pollock, C. J.; Kern, J.; Beckwith, M. A.; Yachandra, V. K.; Pecoraro, V. L.; Yano, J.; Neese, F.; DeBeer, S. The Protonation States of Oxo-Bridged $\mathrm{Mn}^{\mathrm{IV}}$ Dimers Resolved by Experimental and Computational Mn K PreEdge X-ray Absorption Spectroscopy. Inorg. Chem. 2013, 52 (22), 12904-12914.

(37) Pollock, C. J.; Grubel, K.; Holland, P. L.; DeBeer, S. Experimentally Quantifying Small-Molecule Bond Activation Using Valence-to-Core X-ray Emission Spectroscopy. J. Am. Chem. Soc. 2013, 135 (32), 11803-11808.

(38) Pollock, C. J.; Lancaster, K. M.; Finkelstein, K. D.; DeBeer, S. Study of Iron Dimers Reveals Angular Dependence of Valence-toCore X-ray Emission Spectra. Inorg. Chem. 2014, 53 (19), 1037810385.

(39) Rees, J. A.; Martin-Diaconescu, V.; Kovacs, J. A.; DeBeer, S. Xray Absorption and Emission Study of Dioxygen Activation by a Small-Molecule Manganese Complex. Inorg. Chem. 2015, 54 (13), 6410-6422.

(40) Cutsail, G. E.; Gagnon, N. L.; Spaeth, A. D.; Tolman, W. B.; DeBeer, S. Valence-to-Core X-ray Emission Spectroscopy as a Probe of $\mathrm{O}-\mathrm{O}$ Bond Activation in $\mathrm{Cu} 2 \mathrm{O} 2$ Complexes. Angew. Chem., Int. Ed. 2019, 58 (27), 9114-9119.

(41) Perera, R. C. C.; Barth, J.; LaVilla, R. R.; Nordling, C. X-Ray $\mathrm{L} \beta_{2,15}$ Emission Spectrum of $\mathrm{Ru}$ in $\mathrm{Ru}\left(\mathrm{NH}_{3}\right)_{6} \mathrm{Cl}_{3}$. EXAFS and Near Edge Structure III 1984, 2, 501-503. 
(42) Singh, S. K.; Eng, J.; Atanasov, M.; Neese, F. Covalency and chemical bonding in transition metal complexes: An ab initio based ligand field perspective. Coord. Chem. Rev. 2017, 344, 2-25.

(43) Evans, I. P.; Spencer, A.; Wilkinson, G. Dichlorotetrakis(dimethyl sulfoxide)ruthenium(II) and its use as a source material for some new ruthenium(II) complexes. J. Chem. Soc., Dalton Trans. 1973, No. 2, 204-209.

(44) Rossi, M. B.; Piro, O. E.; Castellano, E. E.; Alborés, P.; Baraldo, L. M. Reactivity and Spectroscopy of the $\left\{\mathrm{Ru}(\mathrm{DMAP})_{5}\right\}$ Fragment: An $\left\{\mathrm{Ru}\left(\mathrm{NH}_{3}\right)_{5}\right\}$ Analogue. Inorg. Chem. 2008, 47 (7), 2416-2427.

(45) Bernhard, P.; Sargeson, A. M. Synthesis and Properties of the $\mathrm{Ru}(\operatorname{tacn})_{2}{ }^{3+/ 2+}$ Couple and NMR Study of the Electron Self-Exchange $(\operatorname{tacn}=1,4,7$-Triazacyclononane). Inorg. Chem. 1988, 27 (15), 25822587.

(46) Thompson, A. C.; Attwood, D.; Gullikson, E.; Howells, M.; Kim, K. J.; Kirz, J.; Kortight, J.; Lindau, I.; Lui, Y.; Pianetta, P.; Robinson, A.; Scofield, J.; Underwood, J.; Williams, G. X-Ray Data Booklet, 3rd ed.; Lawrence Berkeley National Laboratory, University of California: Berkeley, CA, 2009.

(47) Neese, F. The ORCA program system. Wiley Interdiscip. Rev.: Comput. Mol. Sci. 2012, 2, 73-78.

(48) Neese, F. Software update: The ORCA program system, version 4.0. Wiley Interdiscip. Rev.: Comput. Mol. Sci. 2018, 8, 4-9.

(49) Becke, A. D. Density functional calculations of molecular bond energies. J. Chem. Phys. 1986, 84 (8), 4524-4529.

(50) Becke, A. D. Density-functional thermochemistry. III. The role of exact exchange. J. Chem. Phys. 1993, 98 (7), 5648-5652.

(51) Perdew, J. P. Density-functional approximation for the correlation energy of the inhomogeneous electron gas. Phys. Rev. B: Condens. Matter Mater. Phys. 1986, 33 (12), 8822-8824.

(52) Lee, C.; Yang, W.; Parr, R. G. Development of the ColleSalvetti correlation-energy formula into a functional of the electron density. Phys. Rev. B: Condens. Matter Mater. Phys. 1988, 37 (2), 785789.

(53) Weigend, F. Accurate Coulomb-fitting basis sets for $\mathrm{H}$ to $\mathrm{Rn}$. Phys. Chem. Chem. Phys. 2006, 8 (9), 1057-1065.

(54) Stoychev, G. L.; Auer, A. A.; Neese, F. Automatic Generation of Auxiliary Basis Sets. J. Chem. Theory Comput. 2017, 13 (2), 554-562.

(55) Fischer, T. H.; Almlöf, J. General methods for geometry and wave function optimization. J. Phys. Chem. 1992, 96 (24), 97689774.

(56) Neese, F. Approximate second-order SCF convergence for spin unrestricted wavefunctions. Chem. Phys. Lett. 2000, 325 (1-3), 9398.

(57) Garcia-Ratés, M.; Neese, F. Effect of the Solute Cavity on the Solvation Energy and its Derivatives within the Framework of the Gaussian Charge Scheme. J. Comput. Chem. 2020, 41, 922-939.

(58) Lee, N.; Petrenko, T.; Bergmann, U.; Neese, F.; DeBeer, S. Probing Valence Orbital Composition with Iron $\mathrm{K} \beta$ X-ray Emission Spectroscopy. J. Am. Chem. Soc. 2010, 132 (28), 9715.

(59) Pettersen, E. F.; Goddard, T. D.; Huang, C. C.; Couch, G. S.; Greenblatt, D. M.; Meng, E. C.; Ferrin, T. E. UCSF Chimera-a visualization system for exploratory research and analysis. J. Comput. Chem. 2004, 25 (13), 1605-1612.

(60) Mathe, Z.; Pantazis, D. A.; Lee, H. B.; Gnewkow, R.; Van Kuiken, B. E.; Agapie, T.; DeBeer, S. Calcium Valence-to-Core X-ray Emission Spectroscopy: A Sensitive Probe of Oxo Protonation in Structural Models of the Oxygen-Evolving Complex. Inorg. Chem. 2019, 58 (23), 16292-16301.

(61) Valenza, R. A.; Jahrman, E. P.; Kas, J. J.; Seidler, G. T. Doubleionization satellites in the x-ray emission spectrum of Ni metal. Phys. Rev. A: At., Mol., Opt. Phys. 2017, 96 (3), 032504.

(62) Galambosi, S.; Sutinen, H.; Mattila, A.; Hämäläinen, K.; Sharon, R.; Kao, C. C.; Deutsch, M. Near-threshold multielectronic effects in the $\mathrm{Cu}$ [Formula Presented] x-ray spectrum. Phys. Rev. A: At., Mol., Opt. Phys. 2003, 67 (2), 5-5.

(63) Enkisch, H.; Sternemann, C.; Paulus, M.; Volmer, M.; Schülke, W. 3D spectator hole satellites of the $\mathrm{Cu} \mathrm{K} \beta_{1,3}$ and $\mathrm{K} \beta_{2,5}$ emission spectrum. Phys. Rev. A: At., Mol., Opt. Phys. 2004, 70 (2), 022508.
(64) Mortensen, D. R.; Seidler, G. T.; Kas, J. J.; Govind, N.; Schwartz, C. P.; Pemmaraju, S.; Prendergast, D. G. Benchmark results and theoretical treatments for valence-to-core $\mathrm{x}$-ray emission spectroscopy in transition metal compounds. Phys. Rev. B: Condens. Matter Mater. Phys. 2017, 96 (12), 125136.

(65) Hocking, R. K.; Wasinger, E. C.; De Groot, F. M. F.; Hodgson, K. O.; Hedman, B.; Solomon, E. I. Fe L-edge XAS studies of $\mathrm{K}_{4}\left[\mathrm{Fe}(\mathrm{CN})_{6}\right]$ and $\mathrm{K}_{3}\left[\mathrm{Fe}(\mathrm{CN})_{6}\right]$ : A direct probe of back-bonding. $J$. Am. Chem. Soc. 2006, 128 (32), 10442-10451.

(66) Wasinger, E. C.; De Groot, F. M. F.; Hedman, B.; Hodgson, K. O.; Solomon, E. I. L-edge X-ray Absorption Spectroscopy of NonHeme Iron Sites: Experimental Determination of Differential Orbital Covalency. J. Am. Chem. Soc. 2003, 125 (42), 12894-12906.

(67) Ardo, S.; Meyer, G. J. Photodriven heterogeneous charge transfer with transition-metal compounds anchored to $\mathrm{TiO}_{2}$ semiconductor surfaces. Chem. Soc. Rev. 2009, 38 (1), 115-164.

(68) Daul, C. A.; Weber, J. The electronic structure and low-lying excited states of the ruthenium(II)tris(diimine) complex. Chem. Phys. Lett. 1981, 77 (3), 593-600.

(69) Chandrasekaran, P.; Stieber, S. C. E.; Collins, T. J.; Que, L., Jr.; Neese, F.; DeBeer, S. Prediction of high-valent iron K-edge absorption spectra by time-dependent Density Functional Theory. Dalton Transactions 2011, 40 (42), 11070-11070.

(70) Kamdar, J.; Grotjahn, D. An Overview of Significant Achievements in Ruthenium-Based Molecular Water Oxidation Catalysis. Molecules 2019, 24 (3), 494-494. 